\title{
Drugging the Cancer Kinome: Progress and Challenges in Developing Personalized Molecular Cancer Therapeutics
}

\author{
P. WORKMAN \\ Cancer Research UK Centre for Cancer Therapeutics, The Institute of Cancer Research, \\ Haddow Laboratories, Sutton, Surrey SM2 5NG United Kingdom
}

\begin{abstract}
A major goal of cancer research is to translate our understanding of the causation of malignancy at the level of the genome and biochemical pathways into the development of drugs with improved activity and cancer selectivity. This paper provides a personal perspective of the current status of efforts to achieve this goal, with a particular focus on drugging the cancer kinome. Remarkable progress has been made in this area, but many challenges remain. The value of cancer kinome sequencing is emphasized. Three projects in which the author's laboratory is involved are reviewed in detail. These involve the discovery and development of inhibitors of cyclin-dependent kinases, phosphoinositide 3-kinases, and the Hsp90 molecular chaperone.
\end{abstract}

\section{THE THERAPEUTIC PROMISE OF CANCER GENOMICS}

Just as it is the objective of basic cancer research to understand the fundamental basis of malignancy, so it is the goal of modern molecular therapeutics research to develop drugs that exploit this basic knowledge (Workman and Kaye 2002; Workman 2003a,b; Bronchud et al. 2004). The last five years in particular have seen the translation of our understanding of genomics and molecular biology of cancer into new treatments targeted to pathways responsible for malignancy. In contrast to the drugs developed in the cytotoxic era, the new molecular therapeutics that are being developed in this second golden era of cancer drug development are designed to attack the oncogenic players and pathways that are deranged in cancer: Hence, there is an expectation that these agents will be more efficient and have fewer side effects compared to conventional cytotoxic drugs (Workman 2005)

Although our comprehension of the molecular processes that propel malignancy remains very much incomplete, there is no doubt that the accumulation of genetic and epigenetic abnormalities is critical for cancer progression (Balmain et al. 2003; Vogelstein and Kinzler 2004). These abnormalities in turn produce the hallmark characteristics of cancer, including uncontrolled cell cycle progression and proliferation, inappropriate survival, immortalization, invasion, angiogenesis, and metastasis (Hanahan and Weinberg 2000). It is believed that selection for alterations providing a growth advantage occurs, according to the model of clonal evolution (Nowell 1976). The contribution of various genes to malignant progression is illustrated schematically in Figure 1A, and the exploitation of this knowledge for the development of new therapeutics is depicted alongside in Figure 1B. We now understand very well that the engine of cancer is fueled by the activation oncogenes (which are the "accelerators" of cancer) and the inactivation of tumor suppressor genes (which are the "brakes" on malignancy). In addition, tumor development is encouraged by the mutation and loss of genes involved in DNA repair. Furthermore, the oncogenic process seems to be strongly supported by genes that had been considered previously to play "housekeeping" roles, such as histone deacetylases and the molecular chaperone Hsp90. The ultimate aim must be to identify and understand all of the genes and pathways that are involved in all cancers and to develop drugs that are active in each case.

The choice of molecular targets for cancer drug development is now rooted very firmly in the identification of new cancer genes and the functional pathways that they hijack. High-profile articles in the lay press have helped to fuel public debate about the extent to which the massive investment in cancer research since Richard Nixon's famous "war on cancer" in the 1970s, together with the much-hyped genomic revolution, have already delivered the goods in terms of benefit to patients (Anonymous 2004; Leaf 2004). The clinical activity and regulatory approval of small-molecule drugs like imatinib (Gleevec), gefitinib (Iressa), and erlotinib (Tarceva; see Fig. 2 for structures), and also the therapeutic antibodies trastuzamab (Herceptin), cetuximab (Erbutix), and bevacizumab (Avastin), have provided some reassurance that we are now on the right track. An article published in Business Week while the Symposium meeting was in progress argued that "medical care is reaching a tipping point" and pointed to the 400 cancer drugs that are now in clinical trial, many of which are directed to cancer genome targets (Arnst 2005).

In this paper, I provide a personal perspective on drug development based on cancer genomics, with particular emphasis on "drugging the cancer kinome." I summarize the considerable challenges that face us, as well as the remarkable progress that has been made. I start by discussing cancer kinome targets and focus particularly on the impact of human genome and cancer genome sequencing. I then illustrate many of the issues with exam- 

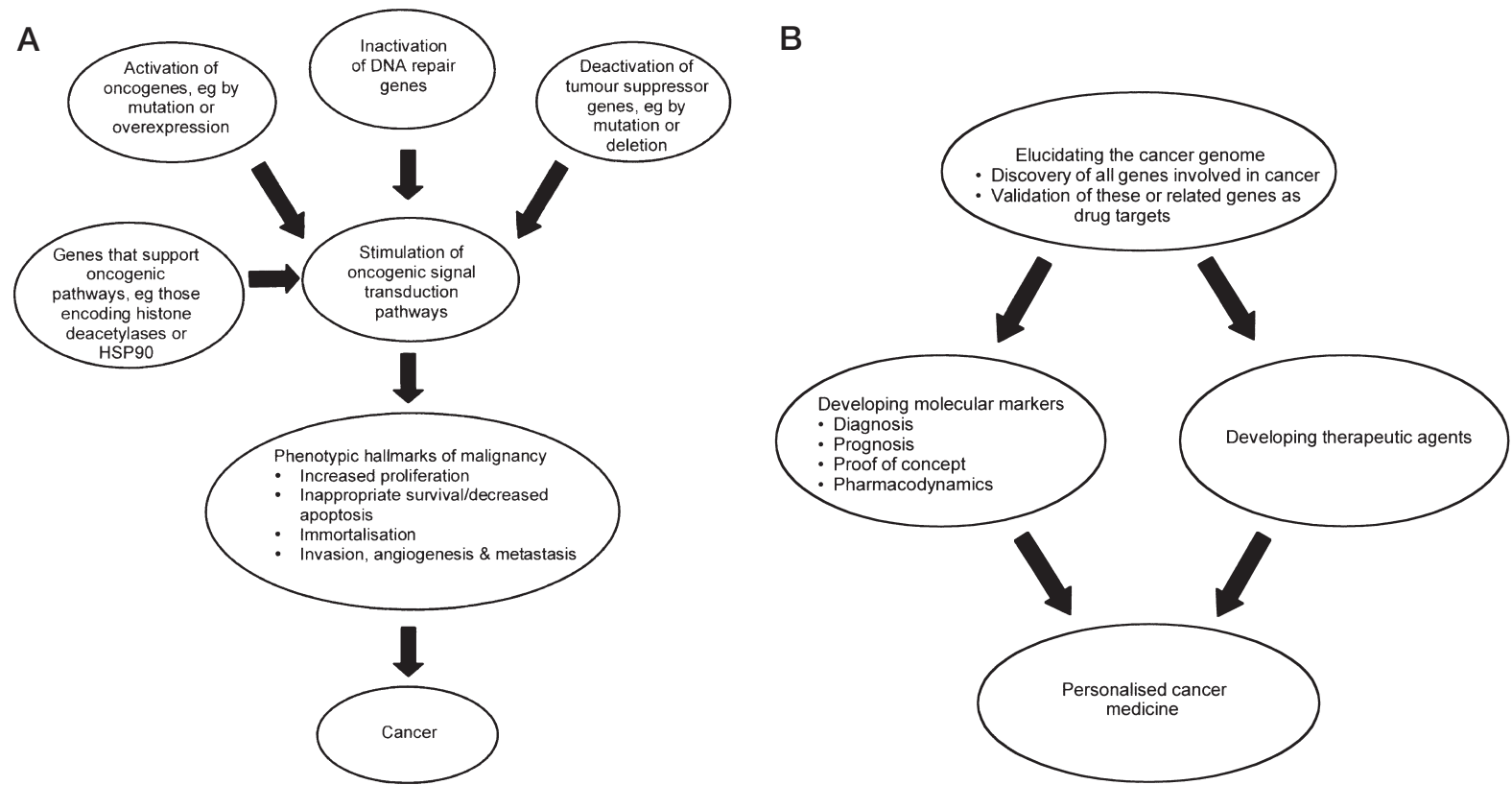

Figure 1. Genomics and contemporary drug development. (A) Schematic illustration of how malignancy is initiated and driven by abnormalities in cancer genes. $(B)$ Exploitation of the cancer genome for the development of targeted molecular therapeutics and personalized cancer treatment. (Modified from Workman 2005.)

ples from our own recent experience in developing smallmolecule inhibitors against three molecular targets, namely cyclin-dependent kinases (CDKs), phosphoinositide 3-kinase (PI3Ks), and the Hsp90 molecular chaperone. The reader is also referred to previous personal views from this author in published interviews (Workman 2001, 2003c).

\section{CANCER KINOME TARGETS}

Oncogenic kinases clearly punch above their weight in the league tables of cancer genes. Of the 291 cancer-causing genes identified in a recent census, $27(6 \%)$ encode protein kinase domains, much higher than the $6(2 \%)$ that would be predicted on the basis of random selection (Futreal et al. 2004). The druggability of kinases as a target class is confirmed by the examples listed in the previous section of this paper. As mentioned, both antibodybased and small-molecule approaches to drugging the cancer kinome have been successful. Kinases now represent the most frequently targeted gene classes in cancer and are second only to G-protein-coupled receptors when ranked across all therapeutic areas (Cohen 2002; Hopkins and Groom 2002).

This has stimulated interest to search for new drug targets among the 518 putative kinases in the human genome (Cohen 2002; Manning et al. 2002). The earliest kinase targets represented the results of decades of painstaking biological research. On the basis of a large body of work, we now know that kinases can be activated in cancer by mutation, translocation, amplification, overexpression, and posttranslational modification. The discovery of kinase targets has recently benefited from the availability of the complete human genome sequence (In- ternational Human Genome Sequencing Consortium 2004) and the application of gene expression profiling by microarray, together with high-throughput mutation detection and high-throughput sequencing approaches (Weir et al. 2004; Workman 2005).

In the first breakthrough made by high-throughput cancer genome sequencing, activating mutations in B-RAF were identified, particularly in melanoma but also in papillary thyroid, serous ovarian, and other cancers (Davies et al. 2002; Garnett and Marais 2004). This discovery immediately stimulated the evaluation in malignant melanoma of sorafenib (formerly known as BAY 439006; see Fig. 2), a multi-targeted kinase inhibitor that blocks B-RAF and C-RAF, among others (Wilhelm et al. 2004). Although single-agent activity was disappointing, striking activity has been seen for sorafenib in combination with cytotoxic chemotherapy in melanoma, and this drug is now being evaluated in randomized trials (Danson and Lorrigan 2005). Because of its action on many kinases, it is difficult to evaluate the role of B-RAF inhibition in the activity of sorafenib, and there is therefore interest in identifying more selective B-RAF inhibitors. A high-throughput screen for inhibitors of the most common V600E B-RAF mutant was carried out in our Centre and identified a 3,5, di-substituted pyridine class of inhibitors (Newbatt et al. 2005).

In addition to the genetics, functional and structural biology studies have now fully validated B-RAF as a bona fide oncogene and drug target (Garnett and Marais 2004; Wan et al. 2004). X-ray crystallography studies of mutant B-RAF with sorafenib showed very elegantly how the V600E mutant promotes the active kinase conformation by disrupting the hydrophobic interaction that occurs between the regulatory activation segment and the glycine- 
<smiles>Cc1ccc(NC(=O)c2ccc(CN3CCN(C)CC3)cc2)cc1Nc1nccc(-c2cccnc2)n1</smiles><smiles>COc1cc2ncnc(Nc3ccc(F)c(Cl)c3)c2cc1OCCCN1CCOCC1</smiles><smiles>C#Cc1cccc(Nc2ncnc3cc(OCCOC)c(OCCOC)cc23)c1</smiles>

Erlotinib<smiles>CNC(=O)c1cc(Oc2ccc(NC(=O)Nc3ccc(Cl)c(C(F)(F)F)c3)cc2)ccn1</smiles><smiles>Cc1nc(Nc2ncc(C(=O)Nc3c(C)cccc3Cl)s2)cc(N2CCN(CCO)CC2)n1</smiles>

BMS-354825<smiles>CCC(CO)Nc1nc(NCc2ccccc2)c2ncn(C(C)C)c2n1</smiles>

Seliciclib<smiles>CN[C@H]1C[C@H]2O[C@](C)([C@@H]1O)n1c3ccccc3c3c4c(c5c6ccccc6n2c5c31)C(=O)NC4O</smiles>

UCN-01<smiles>CN1CCC(c2c(O)cc(O)c3c(=O)cc(-c4ccccc4Cl)oc23)C(O)C1</smiles>

Flavopiridol<smiles>O=C(NOCC1CC1)c1ccc(F)c(F)c1Nc1ccc(I)cc1Cl</smiles>

$\mathrm{Cl}-1040$<smiles>Oc1cccc(-c2nc(N3CCOCC3)c3oc4ncccc4c3n2)c1</smiles>

Figure 2. Chemical structures of various representative small-molecule kinase inhibitory drugs. Imatinib (Gleevec) inhibits BCR$\mathrm{ABL}, \mathrm{KIT}$, and PDFGR receptor kinases and is approved for the treatment of chronic myeloid leukemia and gastrointestinal stromal tumors. Gefitinib (Iressa) and erlotinib (Tarceva) inhibit EGFR and are approved in non-small-cell lung cancer. Sorafenib is an inhibitor of VEFGR-2, VEGFR-3, PDGF $\beta$, RAF, and other kinases and shows activity in renal cancer. BMS-354825 is an inhibitor of SRC and BCR-ABL that retains activity in imatinib-resistant mutants of the latter. UCN-01 is the 7-hydroxy derivative of the prototype broad-spectrum kinase inhibitor staurosporine and inhibits CHK1. Flavopiridol is a broad-spectrum CDK inhibitor that has undergone extensive clinical trials. Seliciclib (CYC202, $R$-roscovitine) is a more selective CDK inhibitor with relatively greater potency for CDKs 2, 7, and 9. CI-1040 is a MEK1/2 inhibitor that entered clinical trials; an analog of this agent is now in clinical development. PI103 is a selective inhibitor of the class 1 PI3K isoforms.

rich P loop. Indeed, almost all of the mutations in the BRAF protein are grouped around these regions, resulting in destabilization of the inactive conformation and stimulation of the enzyme catalytic activity.

Prompted by the success with B-RAF, exon resequencing has been used to probe for somatic mutations in pro- tein kinases, lipid kinases, and phosphatases. In a systematic study of the kinome of colorectal cancers (Bardelli et al. 2003), somatic mutations were identified in 5/90 tyrosine kinase genes (NTKR3, FES, KDR, EHA3, and $M L K 4), 1 / 43$ tyrosine kinase-like genes (MLK4), and one receptor guanylate cyclase gene $(G U C Y 2 F)$. Al- 
though mutations were common in the kinase domains, suggesting potential activation, further work is required to validate these potential drug targets.

A related study of the phosphatome of colorectal cancers identified mutations in the kinase domains of $6 / 87$ members of this superfamily (PTPRF, PTPRG, PTPRT, PTPN3, PTPN13, and PTPN14) (Wang et al. 2004). The mutations indicated the potential for inactivation of the phosphatase activity, suggesting that PRPRT and others may be tumor suppressor genes. If so, therapeutic exploitation would require identification of the corresponding kinases, since pharmacological resurrection of inactive phosphatases is not currently feasible.

A precedent for such an approach comes from work on $P T E N$, which is well known as the second most common tumor suppressor gene after $p 53$. This tumor suppressor gene is implicated in glioblastoma, prostate, and endometrial malignancies (Dahia 2000). PTEN encodes a lipid phosphatase that is responsible for reversing the biochemical reactions that produce phosphatidylinositol 3,4 biphosphate and phosphatidylinositol 3,4,5-triphosphate and are catalyzed by the class I PI3Ks. Systematic sequencing of the coding regions of $8 \mathrm{PI} 3 \mathrm{Ks}$ and another 8 PI3K-like genes led to the discovery of mutations only in the PIK3CA gene (Samuels et al. 2004). This gene encodes the $\mathrm{p} 110 \alpha$ catalytic subunit, a class $1 \mathrm{~A}$ PI3K. The mutations suggested likely activation of the kinase. Activation was demonstrated biochemically in one case, and subsequent studies confirmed this and also showed oncogenic activity (Kang et al. 2005). PI3K3CA mutations have been found in colorectal, glioblastoma, gastric, and breast cancers (Bachman et al. 2004; Samuels et al. 2004). Together with previous evidence for amplification of PIK3CA (Shayesteh et al. 1999) and a wealth of other data, these mutation studies add support for the development of PI3K inhibitors for cancer treatment (Stein and Waterfield 2000; Vivanco and Sawyers 2002; Ward et al. 2003; Drees et al. 2004; Workman 2004a). This is addressed in a later section.

Another externally important example of the value of cancer kinome sequencing is the discovery that activating mutations in the EGFR gene can lead to sensitivity of patients with non-small-cell lung cancer to the EGFR inhibitors gefitinib and erlotinib (Lynch et al. 2004; Paez et al. 2004; Pao et al. 2004). Since I was involved in the gefitinib discovery team at Zeneca (now AstraZeneca), this breakthrough was a particularly exciting one to me personally. The results provide evidence in humans that mutant EGFR is the major driving oncogene in a subset of non-small-cell lung cancers. It is also reasonable to conclude that mutational activation of EGFR in these patients represents an example of "oncogene addiction" (Weinstein 2002), analogous to the role of $B C R-A B L$ in chronic myeloid leukemia and mutant KIT in gastrointestinal stromal tumors (Sawyers 2003; Druker 2004). Subsequent studies have shown that a second mutation in the catalytic domain can lead to resistance to erlotinib and gefitinib (Kobayashi et al. 2005; Pao et al. 2005). Resistance to imatinib can also be caused by similar mutations in the kinase domain of BCR-ABL (Gorre et al. 2001) and can be overcome by an alternative inhibitor BMS-354825 (see Fig. 2) (Shah et al. 2004). This is likely to be a recurring theme (Daub et al. 2004).

\section{CYCLIN-DEPENDENT KINASE INHIBITORS}

Deregulation of cell cycle control proteins by mutation and altered expression is extremely common in human tumors (Sherr 1996, 2000). This led to the idea that smallmolecule catalytic inhibitors of CDKs involved in cell cycle regulation could have therapeutic activity in cancer by minimizing the effects of the natural polypeptide inhibitors that are commonly lost in malignancy (Garrett et al. 2003). Inhibition of CDKs would be expected to lead to cell cycle arrest, and there was also evidence that apoptosis might be induced selectively in cancer cells (Chen et al. 1999).

We have collaborated with Cyclacel Limited in the development of the trisubstituted aminopurine CDK inhibitor seliciclib (CYC202; $R$-roscovitine; see Fig. 2). Seliciclib exhibits its highest level of potency against CDK2/cyclin E, but other CDKs are also affected, particularly CDK1 and the transcriptional kinases CDK7 and 9 that phosphorylate RNA polymerase II and thereby regulate gene transcription (Whittaker et al. 2004). It was difficult to predict which molecular effects would be most important for the antitumor activity of seliciclib. In our mechanism of action studies we used western blotting to study effects on candidate proteins and pathways, and we also employed gene expression profiling using our inhouse cDNA microarray facility as a non-biased, global approach to explore the mechanism of action of seliciclib and to discover potential biomarkers of drug action.

We showed that treatment of human colon cancer cells with seliciclib in tissue culture resulted in a decrease in phosphorylation of the retinoblastoma protein $\mathrm{RB}$ at multiple sites (Whittaker et al. 2004). This was confirmed using an antibody that recognized the hypophosphorylated form at the Ser-608 site. Surprisingly, we also saw an increase in ERK1/2 phosphorylation, but a decrease in FOS protein expression. Furthermore, we saw a reduction in expression of cyclins at both the protein and mRNA levels. In addition, seliciclib caused a decrease in the expression of both the hyperphosphorylated and hypophosphorylated forms of RNA polymerase II, consistent with inhibition of CDKs 7 and 9. Figure 3 shows some of these effects in the HCT116 human colon xenograft in nude mice. No effects are seen on ERK phosphorylation in this model, perhaps because it has a KRAS mutation.

Gene expression microarray profiling showed that around $10-15 \%$ of genes were either up-regulated or down-regulated by seliciclib (Whittaker et al. 2003 and in prep.). Of particular interest was a systematic pattern of reduced expression at the mRNA level of genes involved in the regulation of mitosis, including those encoding cyclin B2, CDC25C, PLK-1, and Aurora-1. Down-regulation was confirmed at the protein level.

We hypothesized that seliciclib was exerting both direct and indirect effects on cell cycle CDKs (Whittaker et al. 2004). There appears to be a direct effect on CDK2, since inhibition of the phosphorylation of the proposed CDK2 site on RB, Thr-821, was an early response to the 
A

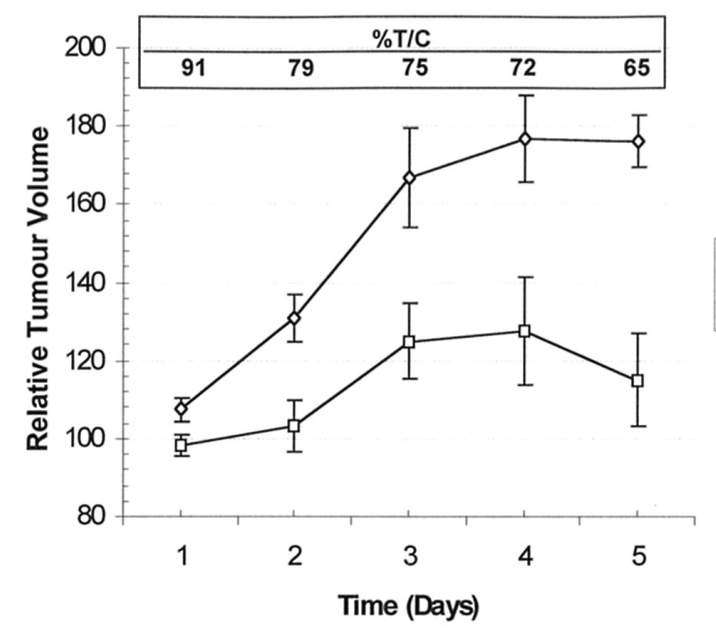

B

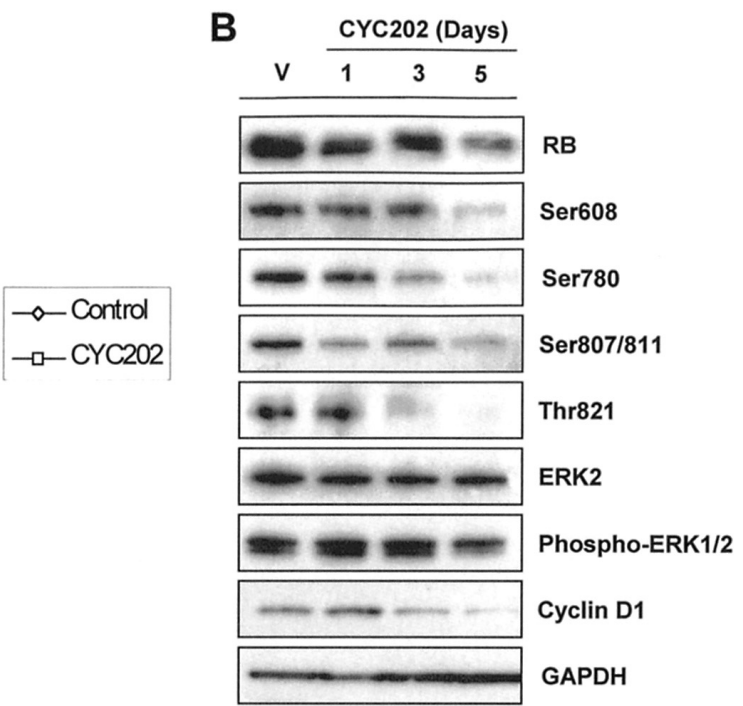

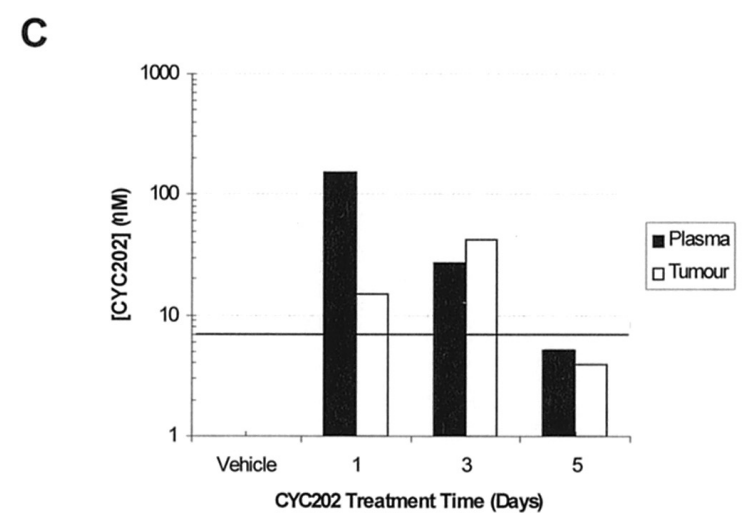

D

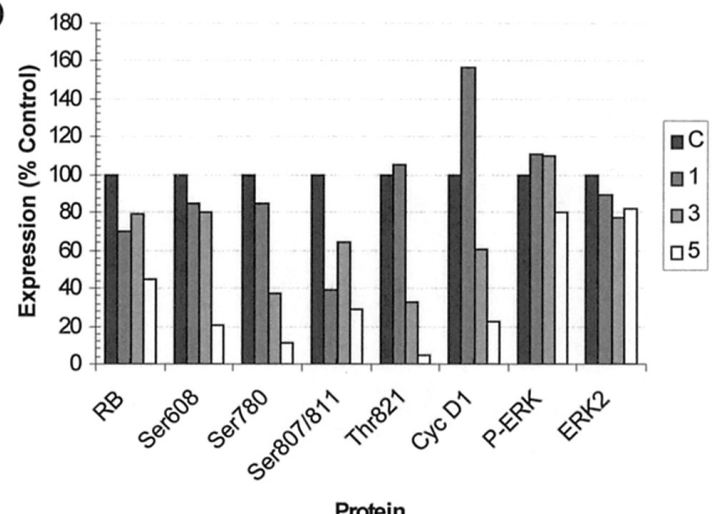

Figure 3. Effects of seliciclib (CYC202, $R$-roscovitine) on human HCT116 human colon cancer xenografts in nude mice. (A) Inhibition of tumor growth. $(B)$ Inhibition of RB phosphorylation and cyclin D1 expression in the tumor tissue of treated animals. $(C)$ Achievement of active drug levels in the tumor tissue. The solid horizontal line indicates the growth inhibitory $\mathrm{IC}_{50}$ for the tumor cells in culture. $(D)$ Quantitation of the changes in molecular markers (shown in $B$ ) by microdensitometry. For more details, see Whittaker et al. (2004), from which the data are taken. The pharmacokinetic-pharmacodynamic data constitute a "pharmacologic audit trail" (see Workman 2002, 2003d,e), which is extremely important to establish in rational, mechanism-based new drug development.

drug. Indirect effects on cell cycle CDKs appear to occur via inhibition of CDKs 7 and 9, leading in turn to inhibition of RNA polymerase II and a reduction in the levels of short-lived mRNAs, including those for multiple cyclins. Depletion of multiple cyclins would deliver a combinatorial blockade of several CDKs simultaneously, thereby explaining the decreased phosphorylation of RB at several different sites. Furthermore, antitumor effects may be associated with down-regulation of transcripts and cognate proteins other than cyclins. For example, we proposed that the down-regulation of mitotic control proteins will have profound effects on the cell cycle at the G2M phase. In addition, we (Whittaker et al. 2003 and in prep.) and others (Alvi et al. 2005; MacCallum 2005) have shown that seliciclib reduces the expression of the antiapoptotic protein MCL1. This could contribute to the apoptotic effects of the drug. In addition, down-regulation of MYC expression could provide an explanation for the reported therapeutic effects of the seliciclib analog purvanalol in a MYC-driven transgenic cancer model (Tward et al., this volume).
The combinatorial pharmacological effects of seliciclib discussed above can be seen as an advantage for this CDK inhibitor. This is because various results show that blockade of CDK2 alone appears to be insufficient for cell proliferation, as demonstrated by various molecular strategies in human colon cancer cell lines and also in CDK2 knockout mice (Berthet et al. 2003; Orteaga et al. 2003; Tetsu and McCormick 2003). This example illustrates a general issue of current interest with kinase inhibitors: the value of highly targeted agents versus those with some degree of multi-kinase inhibition.

The mechanistic insights provided by the various mRNA and protein profiling studies (Whittaker et al. 2003 and in prep.; Alvi et al. 2005) suggest potential indications for seliciclib in particular tumor types. Our observations in human colon cancer cell lines, described above, suggest that this may be an area in which therapeutic activity might be sought. Seliciclib is being evaluated clinically in B-cell chronic lymphocytic leukemia and mantle cell lymphoma, where down-regulation of MCL1 and other survival proteins may be advantageous, 
and also in non-small-cell lung cancer (Guzi 2004). It has recently been shown that melanoma may be an interesting target for seliciclib and related agents, since CDK2 may have a critical role in this cancer linked to its melanocyte-specific transcriptional regulation by MITF (Du et al. 2004).

Another application of the molecular profiling studies described above is the identification of pharmacodynamic biomarkers that can be used to show proof of concept for drug action at the proposed molecular target, as well as to select the optimum drug dose and schedule (Workman 2002, 2003d,e). We have defined pharmacokinetic-pharmacodynamic relationships for seliciclib in a human colon cancer xenograft model, demonstrating, for example, inhibition of RB phosphorylation and a reduction in cyclin expression in this system (Raynaud et al. 2005). Figure 3 shows that these molecular changes are seen when active drug levels are achieved in the tumor tissue and that this is associated in turn with inhibition of tumor growth.

In the search for purine-based CDK inhibitors with the best properties, we have employed the technique of cassette dosing, which allows a higher throughput by the use of compound mixtures, to study the pharmacokinetic properties of over 100 analogs of seliciclib in the mouse (Raynaud et al. 2004). We have also shown that seliciclib is rapidly and extensively converted to the carboxylate metabolite in this species (Nutley et al. 2005), an effect also seen in the phase I clinical trials of the drug carried out at our institution (Benson et al. 2003) and elsewhere (Guzi 2004). On the basis of these studies, we have designed second-generation inhibitors with improved potency and pharmacokinetic/metabolic properties.

\section{PHOSPHOINOSITIDE 3-KINASE INHIBITORS}

Earlier in this paper, evidence was reviewed that supports PI3K as a drug target, particularly in cancers that show evidence of up-regulation of, and molecular dependence on, this pathway (Stein and Waterfield 2000; Vivanco and Sawyers 2002; Workman 2004a). In addition to mutation and overexpression of the PIK3CA gene that encodes the $\mathrm{p} 110 \alpha$ catalytic subunit, and the loss of the PTEN tumor suppressor, other indicators of deregulation of the PI3K pathway include overexpression and mutation of upstream tyrosine kinase receptors; overexpression and activation of the downstream serine-threonine kinase AKT/PKB; mutation and overexpression of the $R A S$ family, which can be placed both upstream and downstream of PI3K; and finally, up-regulation of the PI3K-AKT pathway in resistance to EGFR inhibitors (Sordella et al. 2004). Taken together, these multiple molecular abnormalities provide extremely powerful genetic and biochemical validation for PI3K as a drug target. This is supported by evidence from mouse models of cancer, for example, as presented by several speakers at the Symposium meeting.

To date, relatively few PI3K inhibitors have been identified. Moreover, these have considerable limitations, including weak potency, poor PI3K isoform or more general kinase selectivity, very limited stability and/or poor pharmacokinetic/metabolic properties. However, PI3K inhibitors have begun to emerge recently that have more attractive, drug-like properties and potential for therapeutic activity (Stein and Waterfield 2000; Ward et al. 2003; Drees et al. 2004; Workman 2004a). On balance, the available evidence indicates that the class $1 \mathrm{~A}$ PI3K isoforms $\mathrm{p} 110 \alpha$ and $\mathrm{p} 110 \beta$ may be the most appropriate to concentrate on initially for cancer therapy. Much of the target validation work has focused on p $110 \alpha$, but siRNA knockdown experiments also suggest that inhibition of p110 $\beta$ could be important (Czauderna et al. 2003).

A collaboration was established involving the Ludwig Institute for Cancer Research at University College London, Cancer Research UK, The Institute of Cancer Research, and the Yamanouchi Pharmaceutical Company. This led to the identification of a series of compounds that have the properties of highly selective and extremely potent inhibitors of the class $1 \mathrm{~A}$ PI3Ks. We are now developing the pyridofuropyrimidine (PFP) series in collaboration with PIramed Limited.

PI103 (see Fig. 2) is an example of the PFP series that has been studied in depth (Ahmadi et al. 2004; Guillard et al. 2004; Patel et al. 2004; Workman et al. 2004). PI103 exhibited $\mathrm{IC}_{50}$ values against recombinant class $1 \mathrm{~A}$ enzymes p $110 \alpha, \mathrm{p} 110 \beta$, and $\mathrm{p} 110 \delta$ of $2-3 \mathrm{nM}$, compared to $15 \mathrm{~nm}$ for the class $1 \mathrm{~B}$ isoform $\mathrm{p} 110 \gamma$ and $3.85 \mu \mathrm{M}$ for the class III isoform $\mathrm{Vps} 34$. In addition, $\mathrm{IC}_{50}$ values for PKA and PKC enzymes were $>1 \mu \mathrm{M}$. PI103 inhibited the proliferation of a wide range of human cancer cell lines in culture. For example, in the case of the PC3 prostate cancer cell line, which is PTEN negative and exhibits high levels of phospho-AKT, 50\% growth inhibition was achieved at an exposure concentration of $100 \mathrm{nM}$ for 4 days. PI103 caused a rapid and concentration-dependent inhibition of AKT phosphorylation at both the Ser-473 and Thr-308 sites. In addition, down-regulation of cyclin D1 was seen. A very tight $G_{1}$ arrest was the predominant cellular response in cancer cell lines. Apoptosis was also induced in certain lines but, perhaps surprisingly, is not the predominant phenotypic response. We have looked in particular detail at the properties of PI103 in human glioma cell lines, with a view to potential therapeutic evaluation in this setting, among others. Once again, promising growth inhibitory activity was seen, and this was again associated with the molecular marker changes listed in the preceding paragraph. Over and above the effects of PI103 on cancer proliferation, the compound also inhibited both the motility and the invasive properties of tumor and endothelial cells.

Pharmacokinetic studies showed a volume of distribution $(\mathrm{Vz})$ of $150 \mathrm{ml}$ and a clearance (CL) of $120 \mathrm{ml} / \mathrm{hr}$. Inhibition of the growth of human tumor xenografts was seen, including the U87MG glioblastoma. PI103 was also active in the OVCAR3 human cancer xenograft model, and this was associated with a reduction in the phosphorylation of AKT.

Further medicinal chemistry optimization, based on PI103 as a starting point, has resulted in second-generation PI3K inhibitors showing promising pharmacological activity and improved physicochemical properties, including much greater aqueous solubility at physiological 
$\mathrm{pH}$. At the same time, these second-generation compounds retain high potency and selectivity against $\mathrm{p} 110 \alpha$, $\beta$, and $\delta$, with no inhibitory activity against a panel of 72 kinases representative of the human kinome (Manning et al. 2002) when tested at a concentration of $0.5 \mu \mathrm{M}$. This demonstrates a very high degree of kinase selectivity.

The analog PI540 exhibited an aqueous solubility in excess of $100 \mu \mathrm{M}$, as compared to $3.5 \mu \mathrm{M}$ for the earlier lead PI103. In terms of stability in mouse liver microsomes, PI540 was 91\% stable at 30 minutes compared to a value of $13 \%$ for PI103. CaCo-2 cell permeability studies predicted good cellular uptake properties. No inhibitory activity was noted against the principal form of human cytochrome P450. In addition, PI540 did not inhibit hERG channel activity when assayed using the rubidium efflux method. PI540 exhibited good therapeutic activity in several different human tumor xenograft models, and these included glioblastoma and other cancers that exhibit molecular abnormalities that are likely to be predictive of molecular dependence on the PI3K signaling pathway. Of importance is that this class of inhibitors retains activity against recombinant forms of two of the common $\mathrm{p} 110 \alpha$ mutants that have been reported, and that activity is seen in cell lines reported to harbor these mutations.

Of particular interest with respect to these potent and selective small-molecule inhibitors of PI3K is that they exhibit effects on several of the hallmark traits of malignancy (Hanahan and Weinberg 2000), including proliferation, survival, invasion, metastasis, and angiogenesis. In view of this, PI3K inhibitors may have the potential to deliver stand-alone single-agent therapeutic activity. Alternatively, they may be given in combination with cytotoxics, or with other molecular therapeutics. The optimal combinations will require careful consideration and would ideally be based on rational approaches focused on molecular pathology and pathway dependence (Jackman et al. 2004). Targeted use of PI3K inhibitors in patients with high activity of this pathway, and molecular dependence on it, is a major opportunity to be addressed.

\section{Hsp90 MOLECULAR CHAPERONE INHIBITORS}

Understanding the efficient folding of newly synthesized proteins into their unique, functionally active, three-dimensional structures remains a fundamental problem in biology (Dobson and Karplus 1999). Although the native fold is encoded in the amino acid sequence, the successful folding of many proteins in the crowded environment of the cell requires active assistance from a range of molecular chaperones (Bukau et al. 2000; Hartl and Hayer-Hartl 2002; Young et al. 2004). The complex chaperone machinery of the cell, together with the input of metabolic energy, is essential to prevent misfolding and aggregation into nonnative states in which hydrophobic amino acid residues and unstructured regions of the polypeptide backbone are exposed to solvent (Bukau et al. 2000; Hartl and Hayer-Hartl 2002; Young et al. 2004). In certain cases, aggregation can lead to production of fibrillar structures known as amyloid that are associated with many pathological conditions, includ- ing Huntington's, Alzheimer's, and other diseases (Dobson 1999; Radford 2000).

In addition to preventing aggregation and encouraging productive de novo folding under normal conditions, the chaperone machinery of the cell is also needed under stress conditions, such as elevated temperatures, when unfolding of native proteins can occur. Many chaperones show increased expression under such conditions and are referred to as stress or heat shock proteins or Hsps (Morimoto 1998; Gething and Sambrook 2000).

A large number of chaperones are involved in the orchestration of native protein folding and the stress response (Bukau et al. 2000; Hartl and Hayer-Hartl 2002; Young et al. 2004). In the mammalian cytosol, nascent chains that emerge from the peptide exit tunnel of the ribosome interact with the nascent-chain-associated complex or NAC (Wang et al. 1995). After this, most small proteins do not require additional chaperones. Longer polypeptide chains interact subsequently with the classic Hsp70s and prefoldin, which, in addition to stabilizing elongating chains, can promote cotranslational and posttranslational folding and can also facilitate transfer to downstream chaperones (Deuerling et al. 1999). A fairly restricted group of proteins that are slow in folding and are sensitive to aggregation are dependent on chaperonins, which are large cylindrical double-ring complexes, exemplified by the Group II oligomeric chaperonin of the eukaryotic cytosol known as the TCP-1 ring complex (TriC) or as the chaperonin-containing TCP-1 (CCT) (Bukau et al. 2000; Hartl and Hayer-Hartl 2002; Young et al. 2004). The most abundant substrates for folding by CCT are the cytoskeletal proteins actin and tubulin (Llorca et al. 2000, 2001). It is possible that CCT may play a somewhat broader role, since around 70 proteins can be co-precipitated with it (Thulasiraman et al. 1999) and the von Hippel-Lindau tumor suppressor and WD40repeat, 7-blade propeller proteins are emerging as substrates (Frydman 2001; Valpuesta et al. 2002).

A particular group of cellular proteins, including many kinases and other signal transduction proteins such as steroid hormone receptors, require the specialized chaperone system based on Hsp90 for their folding, stability, and functional regulation (Buchner 1999; Young et al. 2001; Maloney and Workman 2002; Wegele et al. 2004). A list of Hsp90-interacting proteins is available (http://www.picard.ch/downloads/Hsp90interactors.pdf) and among the known Hsp90 clients is a rogues' gallery of oncogenic proteins (Maloney and Workman 2002; Isaacs et al. 2003). Hsp90 works in close collaboration with other co-chaperones, including Hsp70. Substrate transfer from the Hsp70 family member Hsc70 is mediated by the adapter protein Hop/p60, which binds to the extended carboxy-terminal sequence of the two chaperones via its tetratricopeptide repeat (TPR) domains (Scheufler et al. 2000). In addition to its protein-folding role, Hsp90 is also involved in regulating the transfer of nonnative or misfolded proteins to the ubiquitin-proteasome degradation machinery. The ubiquitin ligase CHIP binds to Hsp90 via an amino-terminal TPR domain, thereby targeting Hsp90 substrates for degradation (Connell et al. 2001; Demand et al. 2001). In addition, CHIP 
cooperates with BAG-1, which binds to both the proteasome and Hsc70 (Luders et al. 2000). These interactions indicate a key role for the chaperones Hsp90 and Hsc70 in the integration of folding versus proteasomal degradation and hence in protein quality control in the cell.

Molecular chaperones may not, at first sight, be obvious candidates for selection as cancer drug targets. They are not, to our knowledge, subject to mutation or amplification. Interestingly, however, there is an extensive literature indicating that Hsp90 and Hsp70 can be overexpressed in human cancers (Maloney and Workman 2002). Furthermore, the requirement for Hsp90 in the folding, stability, and functional regulation of a celebrity A-list of oncoproteins suggests that inhibition of Hsp90 may provide simultaneous, combinatorial blockade of multiple oncogenic pathways (Workman 2004b) as well as offering a means to modulate all of the hallmark traits of the disease, including unrestricted proliferation and cell cycle progression, inappropriate survival, immortalization, invasion, angiogenesis, and metastasis (Hanahan and Weinberg 2000). In addition, cancer cells are in a stressed state due to the effects of deregulated oncogenes and tumor suppressor genes, together with environmental effects in solid tumors such as hypoxia, acidosis, and nutrient deprivation (Whitesell et al. 2003; Mosser and Morimoto 2004). These factors may lead to greater dependence on Hsp90 and other chaperones in cancer versus normal cells; for example, by driving Hsp90 into a high-affinity, activated superchaperone complex that is much more sensitive to inhibitors (Kamal et al. 2003; Workman 2004c). It is well established that molecular chaperones such as Hsp90, Hsp70, and Hsp27 are overexpressed in various malignancies, and these proteins have been suggested to be of prognostic value in breast, renal, and endometrial cancers (for review, see Jolly and Morimoto 2000; Maloney and Workman 2002). Increased expression of Hsp90 helps the cancer cell to deal with stresses associated with mutation and overexpression of oncogenes as well as microenvironmental challenges present within solid tumors (Whitesell et al. 2003; Mosser and Morimoto 2004). It has been reported that the sensitivity of cancer cells to Hsp90 inhibitors may be due, at least in part, to the engagement of the chaperone within malignant cells in an activated, high-affinity superchaperone complex that is much more sensitive to Hsp90 inhibitors compared to the uncomplexed Hsp90 in normal cells (Kamal et al. 2003; Workman 2004c). This may provide part of the explanation for why Hsp90 inhibitors such as 17-AAG accumulate preferentially in cancer cells and tissues (Egorin et al. 2002; Chiosis et al. 2003a; Workman 2003e).

Of particular importance is that Hsp90 is essential for the stability and function of many oncogenic client proteins, including ERBB2, BCR-ABL, AKT/PKB, C-RAF, CDK4, PLK-1, MET, mutant p53, HIF-1 $\alpha$, estrogen and androgen receptors, and telomerase hTERT (Maloney and Workman 2002; Wegele et al. 2004). Since Hsp90 inhibition drives client protein depletion via the ubiquitinproteasome pathway (Schulte et al. 1995; Schneider et al. 1996), this will result in the simultaneous combinatorial depletion of multiple oncoproteins, blockade of many oncogenic pathways, and modulation of all the hallmark traits of cancer (Workman 2004b,c). These combinatorial effects should not only be valuable in treating cancers driven by multiple molecular abnormalities, but should also reduce opportunities for resistance to develop. An additional attractive possibility for selective effects on cancer versus normal cells is that Hsp90 may act as a buffer against the potentially damaging effects of mutations that accumulate during malignant progression, analogous to the role proposed for the chaperone in buffering phenotypic variation in the environment (Rutherford and Lindquist 1998). Thus, Hsp90 inhibitors could deliver a synthetic lethal effect on cancer cells.

Note here that Hsp90 and most of the chaperones discussed above are ATPase enzymes. ATPases are known to be druggable by small molecules and, although current drugs do not act at the ATP site, this presents an important opportunity for drug design, analogous to the successful approach with ATP-mimetics in the kinase area (Chene 2002). However, it is known that natural products of the geldanamycin and radicicol classes exert their anticancer activity by binding at the amino-terminal ATP site of Hsp90 (Roe et al. 1999). This had led to an explosion of interest in Hsp90 inhibitors (Solit et al. 2003; Chiosis et al. 2004; Dymock et al. 2004).

Our interest in developing inhibitors of molecular chaperones for cancer treatment can be envisaged as part of an overall conceptual framework in which we seek to attack cancer cells not only by targeting specific molecular abnormalities, but also by inhibiting critical support functions on which cancer cells appear to be more dependent than normal cells (Workman 2005). These systems include chaperones, chromatin-modifying enzymes such as histone deacetylases, and the proteasome machinery. Molecular chaperones are especially attractive targets because of the growing evidence of their key role in managing the cellular stress associated with oncogenesis and malignant progression (Mosser and Morimoto 2004). The regulatory approval of the proteasome inhibitor bortezomib has established the principle that clinical value can be gained with drugs that interfere with the protein quality machinery of the cell (Adams 2002; Mitsiades et al. 2005). Thus, we hypothesize that there is potential for a new range of drugs that modulate protein folding and degradation in cancer and other diseases.

We carried out one of the initial group of Phase I clinical trials on the first-in-class Hsp90 inhibitor 17-AAG, which is an analog of the natural product geldanamycin (Fig. 4) (Banerji et al. 2005b). This study provided the first proof of concept for Hsp90 inhibition, measured by client protein and heat shock protein expression in the tumor tissue of treated patients, in addition to similar effects on peripheral blood lymphocytes that were also reported by ourselves and other workers (Goetz et al. 2005; Grem et al. 2005). The molecular biomarkers that we selected for use in the trial were based on our own cDNA microarray gene expression and proteomic profiling studies (see below), as well as published literature, and were validated by pharmacokinetic-pharmacodynamic relationships obtained in a human tumor xenograft model (Banerji et al. 2005a; and see below). Analysis by west- 


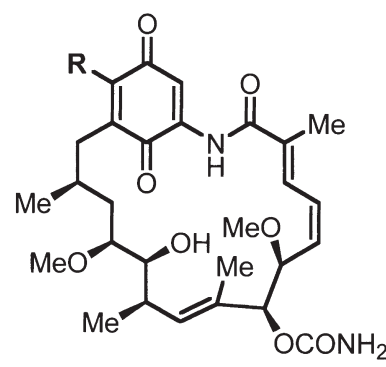

$$
\begin{array}{ll}
\text { Geldanamycin } & \mathrm{R}=\mathrm{OCH}_{3} \\
\text { 17-AAG } & \mathrm{R}=\mathrm{NHCH}_{2} \mathrm{CH}=\mathrm{CH}_{2} \\
\text { 17-DMAG } & \mathrm{R}=\mathrm{NHCH}_{2} \mathrm{CH}_{2} \mathrm{~N}\left(\mathrm{CH}_{3}\right)_{2}
\end{array}
$$<smiles>CCCCn1c(Cc2cc(OC)c(OC)c(OC)c2)nc2c(N)ncnc21</smiles>

PU3<smiles>CCc1cc(-c2n[nH]c(C)c2-c2ccc3c(c2)OCCO3)c(O)cc1O</smiles>

CCT018159 (VER28535)<smiles>O=C(COC(=O)c1ccccc1)Cc1c(Cl)c(O)cc(O)c1CC1CC2C=CC=CC1O2</smiles>

Radicicol<smiles>C#CCCCn1c(Cc2cc(OC)ccc2OC)nc2c(N)nc(F)nc21</smiles>

CCT072671 (VER40994)<smiles>CCNC(=O)c1[nH]nc(-c2cc(Cl)c(O)cc2O)c1-c1ccc(OC)cc1</smiles>

CCT129397 (VER49009)

Figure 4. Chemical structures of representative Hsp90 inhibitors. Geldanamycin and radicicol are natural product inhibitors. 17-AAG and 17-DMAG are geldanamycin analogs that are undergoing early clinical trials. PU3 and CCT072671 (VER40994) are examples of purine inhibitors developed by structure-based design. CCT018159 (VER28535) is a 3,4-diarylpyrazole discovered by highthroughput screening, and CCT129397 (VER49009) is a more potent analog designed from the X-ray crystal structure of CCT0180159 bound to Hsp 90 .

ern blotting of tumor biopsies obtained at 24 hours after doses of 320 and $450 \mathrm{mg} / \mathrm{m}^{2} /$ week showed that Hsp72 was up-regulated in 8/9 patients, the CDK4 client protein was depleted in $8 / 9$ patients, and the C-RAF client protein was depleted in 4/6 patients evaluable for this biomarker. The molecular signature of Hsp90 inhibition was maintained in a single patient studied at 1 and 3 days after dosing but was not seen reproducibly at 5 days. Up-regulation of Hsp 72 was demonstrated within the tumor cells by immunohistochemistry in two patients with melanoma. We observed prolonged stable disease for two patients with advanced, metastatic malignant melanoma, leading to a Phase II clinical trial that is now under way at our institution in association with the Royal Free Hospital, London. Mechanistic studies have also been initiated to understand the sensitivity of melanoma cells to 17-AAG (see below).

Our Phase I trial demonstrated that it was feasible, in a once-weekly schedule, to deliver a dose of 17-AAG re- sulting in potentially therapeutic plasma concentrations, Hsp90 target inhibition in tumor tissue, and possible therapeutic activity. However, the formulation was limiting, leading to clinical trials by ourselves and others with the soluble analog 17-DMAG (Hollingshead et al. 2005) and the search for new Hsp90 inhibitor chemotypes (see below).

We have investigated the detailed molecular and cellular consequences of treating cancer cells with $17-\mathrm{AAG}$ for two major reasons: first, to identify genes and proteins that govern sensitivity to Hsp90 inhibitors; and second, to identify molecular biomarkers of Hsp90 inhibition for potential clinical use (Banerji et al. 2003; Maloney et al. 2003). The cDNA gene expression profiling study that we published with 17-AAG was the first with an Hsp90 inhibitor and one of the first to study global expression changes with any drug (Clarke et al. 2000). Using a 4132 cDNA array, we showed that the expression of genes encoding client proteins was not altered at the mRNA level, 
whereas genes coding for Hsp72, Hsc70, keratins 8 and 18 , and caveolin 1 were deregulated by $17-\mathrm{AAG}$ in human colon cancer cells. We observed cell-line-dependent deregulation of HSP90 $\beta$ expression, with the more sensitive HT29 cells showing depletion of the drug target, whereas the more resistant HCT116 cells exhibited induction of HSP90 $\beta$. Thus, we showed that the dynamic regulation of target expression by the drug is likely to be a factor influencing sensitivity to $17-\mathrm{AAG}$.

We also demonstrated in human colon cancer cell lines that combinatorial inhibition of signal transduction, including blockade of both the RAS-RAF-MEK-ERK1/2 and PI3K-PKB pathways, can lead to cell cycle arrest and apoptosis (Hostein et al. 2001). In the same paper, we showed that the KMI2 colon cancer cell line that overexpressed BAG-1 and lacked expression of BAX was unable to undergo apoptosis in response to 17-AAG. We subsequently showed, by comparing the response of HCT116 colon cancer cells in which BAX was knocked out by homologous recombination (Zhang et al. 2000), that this proapoptopic protein is required for apoptosis in response to 17-AAG and that, in its absence, cell death proceeds more slowly and by necrosis (M. Powers et al., unpubl.).

A further detailed study of changes in expression profile in response to 17-AAG was carried out in A2780 human ovarian cancer cells (A. Maloney et al., in prep.). We used both cDNA microarrays and proteomic analysis, the latter in collaboration with Professor Mike Waterfield (Ludwig Institute for Cancer Research, University College London). One of the most important observations was the identification of AHA1, as a stress-regulated cochaperone that activates the essential, inherent ATPase of Hsp90 (Panaretou et al. 2002). We showed that AHA1 was up-regulated at both the mRNA and protein levels by 17-AAG in human cancer cells. We have subsequently used siRNA to knock down AHA1, and preliminary data show that this sensitizes cells to 17-AAG (J. Holmes et al., unpubl.). Thus, AHA1 expression may potentially affect sensitivity to $17-\mathrm{AAG}$ in patients.

In our mRNA and protein profiling studies in A2780 cells, we used both active Hsp90 inhibitors and an inactive analog to distinguish on-target and off-target effects (A. Maloney et al., in prep.). Expected changes, including the up-regulation of various heat shock proteins, were shown in greater detail than previously, with most effects demonstrated to be on-target, including those involving Hsp70-8, Hsp70-2, Hsp90 $\beta$ (but not Hsp90o), Hsp47, and Hsp27-1. A group of MYC-regulated genes, which we also saw down-regulated in our clinical study of gene expression in rectal cancer patients treated with 5-fluorouracil (Clarke et al. 2003), showed reduced expression and may be an antiproliferative signature. The most novel and interesting discovery was that a group of proteins involved in chromatin regulation, acetylation, and methylation exhibited altered expression in response to 17-AAG. The heterochromatin protein HP1 was up-regulated, whereas both the histone acetyltransferase HAT-1 and the arginine methyltransferase PRMT5 (SKBI/JBP1) were down-regulated by the drug. Total cell acetylation was also decreased by 17-AAG. These results are consis- tent with an emerging interaction between protein acetylation and Hsp90 function. For example, histone deacetylase inhibitors may inhibit the chaperone by increasing Hsp90 acetylation (Yu et al. 2002). Studies in model organisms (Sangster et al. 2003; Zhao et al. 2005) also illustrate close links between chromatin and Hsp90. Of particular significance, our immunoprecipitation studies showed for the first time that PRMT5 is a binding partner and potential client protein for Hsp90 (A. Maloney et al., in prep.).

Along with $A H A 1$, heat shock proteins were the genes most robustly and routinely induced by Hsp90 inhibitors (A. Maloney et al., in prep.). We are carrying out a comprehensive series of experiments to understand the role of Hsp90 and Hsp70 family members in governing sensitivity to Hsp90 inhibitors in cancer cells. This has been challenging because of the potential redundancy involved.

In addition to co-chaperones, we have examined the effects of selected client proteins on cellular sensitivity to Hsp90 inhibitors. ERBB2 is one of the most sensitive and potentially important Hsp90 client proteins (Citri et al. 2004). We created an isogenic model in which ERBB2 was overexpressed and functionally active in ERBB2 negative $\mathrm{CH} 1$ ovarian cells. Using this, we showed that ERBB2 overexpression resulted in a fivefold increase in sensitivity to geldanamycin (Smith et al. 2002).

Another important client protein that we have studied is B-RAF. Having observed prolonged stable disease in two melanoma patients in our Phase I trial (Banerji et al. $2005 \mathrm{~b}$ ), we hypothesized that this may be related to the high incidence of $B-R A F$ mutation in this disease (Davies et al. 2002) and that mutant B-RAF may be a sensitive client protein. In collaboration with Dr. Richard Marais, we have shown that the most common V600E mutant of B-RAF is an Hsp90 client protein that is much more dependent on the chaperone than the wild type for stability and activity (de Rocha Dias et al. 2005). We also showed that the majority of other mutant forms of B-RAF are very sensitive to 17 -AAG-mediated proteasomal degradation. Similar results have been obtained by N. Rosen and colleagues (pers. comm.). The structural determinants for the interaction of client proteins with Hsp90 remain unclear (but see Xu et al. 2005). Our results suggest that it is the adoption of the active conformation, rather than the level of activity, that determines sensitivity to 17-AAG. Our demonstration that mutant B-RAF proteins are hypersensitive to Hsp90 inhibition suggests a possible mechanism for the clinical activity of 17-AAG in melanoma.

The tumor suppressor p53 is a client protein that is depleted by 17-AAG (Kelland et al. 1999). The compound pifithrin $\alpha$ was identified in a screen for suppression of p53-mediated trans-activation (Komarov et al. 1999) and subsequently claimed to block "heat shock signaling" (Komarova et al. 2003). However, we identified significant pharmaceutical limitations with pifithrin $\alpha$ and could detect no effects on Hsp90 activity or indeed on p53 function (Walton et al. 2005).

In the search for biomarkers of Hsp90 inhibition, we used a combination of literature information and results from our cDNA microarray gene expression and pro- 
teomic profiling (Clarke et al. 2000; A. Maloney et al., in prep.; see above), together with approaches based on magnetic resonance spectroscopy and positron emission tomography. We validated a molecular signature of client protein and heat shock protein changes for 17-AAG in an ovarian cancer xenograft model and established pharmacokinetic-pharmacodynamic relationships (Banerji et al. 2005a) prior to our Phase I trial (see above). We developed novel solid-phase immunoassays to quantify the molecular signature using the TRF-Cellisa approach (Hardcastle et al. 2005). In collaboration with our magnetic resonance spectroscopy and imaging colleagues, we identified magnetic resonance spectroscopic (MRS) PD biomarkers, comprising increases in phosphocholine and phosphomonoester levels for 17-AAG in human colon cancer models (Chung et al. 2003). This MRS signature was distinct from those we have seen with inhibitors of MEK1/2 (Beloueche-Babari et al. 2005), PI3K (M. Beloueche-Babari et al., in prep.) and choline kinase (AlSaffar et al. 2005). In collaboration with our positron emission tomography collaborators, we have identified radiolabeled choline as a potential marker for Hsp90 inhibition (Liu et al. 2002) as well as radiolabeled annexin $\mathrm{V}$ to image apoptosis (Collingridge et al. 2003). Such assays could be used to image PD effects of Hsp90 inhibitors in animal models and patients alongside assays for client protein degradation (Smith-Jones et al. 2004).

We have demonstrated profound effects of geldanamycin and 17-AAG on key aspects of neoangiogenesis (S. Brader et al., in prep.). Together with other studies (de Candia et al. 2003; Kaur et al. 2004), our results suggest that effects on angiogenesis may play a major role in the response to Hsp90 inhibitors in vivo, consistent with the proposed combinatorial action on the hallmarks of cancer (Workman 2004b).

17-AAG continues to show promise as a first-in-class Hsp90 inhibitor. It does, however, have a number of limitations (Workman 2004b), including its poor solubility and cumbersome formulation; relatively weak target potency; reduced activity in the presence of P-glycoprotein and the absence of DT-diaphorase/NQO1 activity (Brunton et al. 1998; Kelland et al. 1999); and low oral bioavailability and metabolism by polymorphic cytochrome P450 CYP3A4 (Egorin et al. 1998). There is, therefore, a strong case for developing improved secondgeneration inhibitors. We have taken a broad approach to this. We examined a series of 17-AAG analogs available from the U.S. National Cancer Institute; we pursued a structure-based approach to the design of stable and druglike analogs of radicicol; we explored purine-based inhibitors; and we undertook a high-throughput screening approach to identify novel chemotypes.

We studied structure/activity relationships (SAR) for the various pharmacological activities of 24 geldanamycin analogs, focusing on 17-amino-substituted compounds related to 17-AAG (see Fig. 4), since this motif appeared to confer beneficial therapeutic properties for reasons that were not clear. Previous SAR studies had focused on effects on ERBB2, since the Hsp90 mechanism was not defined at that time (Schnur et al. 1995a,b). Overall, we found that there was a consistent SAR linking in- hibition of the ATPase activity of recombinant Hsp90, depletion of C-RAF client protein, induction of HSP70, and cancer cell growth inhibition, consistent with primary action at the Hsp90 target (A. Maloney et al., unpubl.). We derived a specific SAR for the potentiation of antiproliferative activity by NQO1/DT-diaphorase that we discovered (Kelland et al. 1999). This effect was restricted to alkyl-substituted 17-amino analogs, and the greatest differential was seen with 17-AAG itself. In the case of 17-DMAG, in which the 17-allylamino moiety is replaced by 17-diethylaminoethylamino (Fig. 4), the "potentiation factor" was reduced from 24 to 5 in the NQO1+/- isogenic pair that we developed (Sharp et al. 2000). This suggests a significant difference from 17AAG, reducing the risk of a potential resistance mechanism but also decreasing the potential therapeutic advantage in high NQO1-expressing cancers. However, as we noted previously, the NQO1 effect is offset by metabolism to the 17-amino compound which lacks the NQO1 dependence (Kelland et al. 1999). We also characterized the mouse plasma and tissue pharmacokinetics and microsomal metabolism of selected 17-AAG analogs (Smith et al. 2004), incorporating an evaluation of the cassette dosing method that we developed for the CDK inhibitor project (Raynaud et al. 2004).

It remains an intriguing possibility that, as suggested previously (Workman 2004c), reduction of the quinone could be involved in the activity of $17-\mathrm{AAG}$ in the context of the Hsp90 superchaperone complex that was reported to predominate in cancer cells (Kamal et al. 2003). It should be noted that the quinol of 17-AAG is entering clinical trials as a soluble prodrug form (IPI-504; Sydor et al. 2005).

The first series of synthetic drug-like small-molecule Hsp90 inhibitors were the purine analogs designed by Chiosis et al. $(2001,2003 b)$ to mimic the unusual "Cshape" adopted by ADP/ATP in the Hsp90 amino terminus (Prodromou et al. 1997; Stebbins et al. 1997). In collaboration with Vernalis, we determined X-ray co-crystal structures with human HSP90 $\alpha$ and $\beta$ of a lead purine inhibitor PU3 (see Fig. 4) (Wright et al. 2004). We showed that the purine does mimic the adenine of ADP/ADT but, unexpectedly, the trimethoxyphenyl ring induces a conformational change in the loop region capping the ATP site to create a new binding pocket. Crystal structures explained the SAR and allowed the design of more potent analogs, e.g., the 1-pentynyl compound CCT072671 or VER40994 was at least 50 times more active than PU3 (Wright et al. 2004).

We identified the 3,4-diarylpyrazole series in a highthroughput screen of our (then) 53,000 compound collection against the ATPase activity of the full-length recombinant yeast Hsp90 using a malachite green readout (Aherne et al. 2003; Rowlands et al. 2004). Yeast enzyme was used because of its higher ATPase activity, but compounds were confirmed as active against human Hsp90 activated by AHA1 (Panaretou et al. 2002). The initial pyrazole series was exemplified by the $\mu \mathrm{M}$ hit CCT018159 or VER28535 (Fig. 4). The molecular mode of action in cells was confirmed, synthetic routes were developed, and X-ray co-crystal structures obtained with 
Professor Pearl explained early SAR and identified optimization opportunities (Cheung et al. 2005). This led to a research collaboration with Vernalis. Structure-based optimization, particularly the introduction of the 5-amide substitution to gain a hydrogen bond interaction with Gly-97 (human), led to potent analogs; this is exemplified by CCT129397 or VER49009, which has nanomolar activity, compares favorably with 17-AAG, and has the required potency and potential to become a clinical candidate (Dymock et al. 2005). In addition, 4-amino derivatives (X. Barril et al., in prep.) with a similar binding mode to CCT129397 or VER49009 and 3-(5-chloro2,4-dihydroxyphenyl)-pyrazole-4-carboxamides that access interaction via Phe-138 (Brough et al. 2005) were developed. Pyrazoles examined showed a very high degree of selectivity for Hsp90 versus the ATPases of DNA topoisomerase II and Hsp72, as well as a panel of kinases representing the human kinome (Manning et al. 2002). In contrast to 17-AAG, we showed that NQO1 and P-glycoprotein had little effect on sensitivity. We used the SAR and X-ray structures with the 3,4-diarylpyrazole series to design a fluorescent derivative that can be used to measure low-nanomolar $\mathrm{IC}_{50}$ values ( $\mathrm{R}$. Howes et al., in prep.). These studies illustrate the power of high-throughput screening combined with X-ray crystallographydriven, structure-based design and indicate the considerable therapeutic potential of inhibiting the Hsp90 molecular chaperone.

\section{CONCLUDING REMARKS}

Advances in our understanding of the human genome and now the cancer genome are having a major impact on drug development. Our comprehension of the cancer kinome and its exploitation for drug discovery has been especially successful. Drugging the cancer kinome is clearly an achievable goal. Several kinase inhibitors are already approved and many more are in development. Both small-molecule and antibody approaches show great promise.

In this paper, I have mentioned both successes and challenges in developing the more established smallmolecule kinase inhibitors, for example, imatinib and the EGFR inhibitors, as well as emerging inhibitors of CDKs and PI3K. Current issues with kinase inhibitors include:

- Selecting patients based on evidence of molecular dependence and oncogene addiction

- The need for biomarkers of drug action for use in intelligent hypothesis-testing, proof-of-concept clinical trials

- The development of resistance through kinase mutations

- The potential need to inhibit multiple kinases to overcome cancers with multiple abnormalities and to prevent the development of resistance

- The difficulty in selecting and developing rational combination treatments

Several of the limitations with kinase inhibitors can be overcome using inhibitors of the Hsp90 molecular chaperone which provide combinatorial knockdown of multiple cancer kinases and other oncoproteins and simultaneous blockade of many oncogenic pathways (Workman 2003f). Prospects for the development of personalized cancer treatments, targeted to the kinome and genome abnormalities of individual human cancers, are very exciting.

\section{ACKNOWLEDGMENTS}

Thanks to Dr. Ian Collins and Dr. Vassilios Bavetsias for the chemical structure figures and to many colleagues and collaborators for valuable discussions. Work in the author's laboratory (www.icr.ac.uk/cctherap) is funded by Cancer Research UK Programme Grant Number [CUK] C309/A2187; the author is a Cancer Research UK Life Fellow. Work on CDK, PI3K, and Hsp90 was also funded in part by Cyclacel Limited, PIramed Limited, and Vernalis, respectively.

\section{REFERENCES}

Adams J. 2002. Proteasome inhibition: A novel approach to cancer therapy. Trends Mol. Med. (suppl.) 8: S49.

Aherne W., Maloney A., Prodromou C., Rowlands M.G., Hardcastle A., Boxall K., Clarke P., Walton M.I., Pearl L., and Workman P. 2003. Assays for HSP90 and inhibitors. Methods Mol. Med. 85: 149 .

Ahmadi K., Alderton W., Chuckowree I., Depledge P., Folkes A., Pergl-Wilson G., Saghir N., Shuttleworth S., Wan N., Raynaud F., Saghir N.S.S., Wan N.C., and Zhyvoloup A. 2004. Identification of potent, selective, soluble and permeable small molecule PI3 kinase inhibitors for the treatment of cancer. Proceedings of the EORTC-NCI-AACR Symposium on Molecular Targets and Cancer Therapeutics (Abstr. 320). Eur. J. Cancer 2: 8. (Suppl.)

Al Saffar N.M.S., Troy H., Ramirez de Molina A., Jackson L.E., Madhu B., Griffths J.R., Leach M.O., Workman P., Lacal J.C., Judson I.R., and Chung Y.-L. 2005. Non-invasive magnetic resonance spectroscopic pharmacodynamic markers of the choline kinase inhibitor MN58b in human carcinoma models. Cancer Res. (in press).

Alvi A.J., Austen B., Weston V.J., Fegan C., MacCallum D., Gianella-Borradori A., Lane D.P., Hubank M., Powell J.E., Wei W., Taylor A.M., Moss P.A. and Styankovic T. 2005. A novel CDK inhibitor, CYC202 (R-roscovitine), overcomes the defect in p53-dependent apoptosis in B-CLL by down-regulation of genes involved in transcription regulation and survival. Blood 105: 4484.

Anonymous. 2004. The future of cancer treatment: Up close and personal. The Economist, October 16, 2004.

Arnst C. 2005. Biotech, finally. Business Week, June 13, 2005.

Bachman K.E., Argani P., Samuels Y., Silliman N., Ptak J., Szabo S., Konishi H., Karakas B., Blair B.G., Lin C., Peters B.A., Velculescu V.E., and Park B.H. 2004. The PI3KCA gene is mutated in a high frequency in human cancers. Cancer Biol. Ther. 3: 772.

Balmain A., Gray J., and Ponder B. 2003. The genetics and genomics of cancer. Nat. Genet. 33: 288.

Banerji U., Judson I., and Workman P. 2003. The clinical applications of heat shock protein inhibitors in cancer-Present and future. Curr. Cancer Drug Targets 3: 385.

Banerji U., Walton M., Raynaud F., Grimshaw R., Kelland L., Valenti M., Judson I., and Workman P. 2005a. Pharmacokinetic-pharmacodynamic relationships for the HSP90 molecular chaperone inhibitors 17-allylamino, 17-demethoxygeldanamycin (17-AAG) in human ovarian cancer models. Clin. Cancer Res. 11: 7023.

Banerji U., O’Donnell A., Scurr M., Pacey S., Stapleton S., Asad Y., Simmons L., Maloney A., Raynaud F., Campbell M., Walton M., Lakhani S., Kaye S., Workman P., and Judson I. 2005b. Phase I pharmacokinetic and pharmacodynamic study 
of 17-allylamino, 17-demethoxygeldanamycin in patients with advanced malignancies. J. Clin. Oncol. 23: 4152.

Bardelli A., Parsons D.W., Silliman N., Ptak J., Szabo S., Saha S., Markowitz S., Willson J.K., Parmigiani G., Kinzler K.W., Vogelstein B., and Velculescu V.E. 2003. Mutational analysis of the tyrosine kinome in colorectal cancers. Science 300: 949.

Beloueche-Babari M., Jackson L.E., Al-Saffar N.M., Workman P., Leach M.O., and Ronen S.M. 2005. Magnetic resonance spectroscopy monitoring of mitogen-activated protein kinase signaling inhibition. Cancer Res. 65: 3356.

Benson C., White J., Twelves C., O'Donnell A., Cruickshank C., Tan S., Gianella-Borradori A., and Judson I. 2003. A phase I trial of the oral cyclin dependent kinase inhibitor CYC202 in patients with advanced malignancy. Proc. Am. Soc. Clin. Oncol. 22: 209.

Berthet C., Aleem E., Coppola V., Tessarollo L., and Kaldis P. 2003. CDK2 knockout mice are viable. Curr. Biol. 13: 1775.

Bronchud M.H., Foote M.A., Giaccone G, Olopade O., and Workman P., Eds. 2004. Principles of molecular oncology, 2nd. edition. Humana Press, Totowa, New Jersey.

Brough P.A., Barril X., Beswick M., Dymock B.W., Drysdale M.J., Wright L., Grant K., Massey A., Surgenor A., and Workman P. 2005. 3-(5-Chloro-3,4-dihydroxyphenyl)-pyrazole-4-carboxamides as inhibitors of the Hsp90 molecular chaperone. Bioorg. Med. Chem. Lett. 15: 5197.

Brunton V.G., Steele G., Lewis A.D., and Workman P. 1998. Geldanamycin-induced cytotoxicity In human colon cancer cell lines: Evidence against the involvement of c-Src or DTdiaphorase. Cancer Chemother. Pharmacol. 41: 417.

Buchner J. 1999. Hsp90 and Co.-A holding for folding. Trends Biochem. Sci. 24: 136.

Bukau B., Deuerling E., Pfund C., and Craig E. 2000. Getting newly synthesised proteins into shape. Cell 101: 119.

Chen Y.N., Sharma S.K., Ramsey T.M., Jiang L., Martin M.S., Baker K., Adams P.D., Bair K.W., and Kaelin W.G., Jr. 1999. Selective killing of transformed cells by cyclin/cyclin dependent kinase 2 antagonists. Proc. Natl. Acad. Sci. 96: 4325.

Chene P. 2002. ATPases as drug targets: Learning from their structure. Nat. Rev. Drug Discov. 1: 665.

Cheung K.M., Matthews T.P., James K., Rowlands M.G., Boxall K.J., Sharp S.Y., Maloney A., Roe S.M., Prodromou C., Pearl L.H., Aherne G.W., McDonald E., and Workman P. 2005. The identification, synthesis, protein crystal structure and in vitro biochemical evaluation of a new 3,4-diarylpyrazole class of Hsp90 inhibitors. Bioorg. Med. Chem. Lett. 15: 3338.

Chiosis G., Vilenchik M., Kim J., and Solit D. 2004. Hsp90: The vulnerable chaperone. Drug Discov. Today 9: 881.

Chiosis G., Huezo H., Rosen N., Mimnaugh E., Whitesell L., and Neckers L. 2003a. 17AAG: Low target binding affinity and potent cell activity-Finding an explanation. Mol. Cancer Ther. 2: 123.

Chiosis G., Lucas B., Huezo H., Solit D., Basso A., and Rosen N. 2003b. Development of purine-scaffold small molecule inhibitors of Hsp90. Curr. Cancer Drug Targets 3: 371.

Chiosis G., Timaul M.N., Lucas B., Munster P.N., Zheng F.F., Sepp-Lorenzino L., and Rosen N. 2001. A small molecule designed to bind to the adenine nucleotide pocket of Hsp90 causes Her2 degradation and the growth arrest and differentiation of breast cancer cells. Chem. Biol. 8: 289.

Chung Y.L., Troy H., Banerji U., Jackson L.E., Walton M.I., Stubbs M., Griffiths J.R., Judson I.R., Leach M.O., Workman P., and Ronen S.M. 2003. Magnetic resonance spectroscopic pharmacodynamic markers of the heat shock protein 90 inhibitor 17-allylamino,17-demethoxygeldanamycin (17AAG) in human colon cancer models. J. Natl. Cancer Inst. 95: 1624.

Citri A., Kochupurakkal B.S., and Yarden Y. 2004. The achilles heel of ErbB-2/HER2: Regulation by the Hsp90 chaperone machine and potential for pharmacological intervention. Cell Cycle 3: 51.

Clarke P.A., George M.L., Easdale S., Cunningham D., Swift R.I., Hill M.E., Tait D.M., and Workman P. 2003. Molecular pharmacology of cancer therapy in human colorectal cancer by gene expression profiling. Cancer Res. 63: 6855 .

Clarke P.A., Hostein I., Banerji U., Stefano F.D., Maloney A.,
Walton M., Judson I., and Workman P. 2000. Gene expression profiling of colon adenocarcinoma cells following inhibition of signal transduction by 17-allylamino-17demethoxygeldanamycin, an inhibitor of the HSP90 molecular chaperone. Oncogene 19: 4125.

Cohen P. 2002. Protein kinases - The major drug targets of the twenty-first century? Nat. Rev. Drug Discov. 1: 309.

Collingridge D.R., Glaser M., Osman S., Barthel H., Hutchinson O.C., Luthra S.K., Brady F., Bouchier-Hayes L., Martin S.J., Workman P., Price P., and Aboagye E.O. 2003. In vitro selectivity, in vivo biodistribution and tumour uptake of annexin $\mathrm{V}$ radiolabelled with a positron emitting radioisotope. Br. J. Cancer 89: 1327.

Connell P., Ballinger C.A., Jiang J., Wu Y., Thompson L.J., Hohfeld J., and Patterson C. 2001. The co-chaperone CHIP regulates protein triage decisions mediated by heat-shock proteins. Nat. Cell Biol. 3: 93.

Czauderna F., Fechtner M., Aygun H., Arnold W., Klippel A., Giese K., and Kaufmann J. 2003. Functional studies of the $\mathrm{PI}(3)$-kinase signalling pathway employing synthetic and expressed siRNA. Nucleic Acids Res. 31: 670.

Dahia P.L. 2000. PTEN, a unique tumor suppressor gene. Endocr. Relat. Cancer 7: 115.

Danson S. and Lorigan P. 2005. Improving outcomes in advanced malignant melanoma: Update on systemic therapy. Drugs 65: 733.

Daub H., Specht K., and Ullrich A. 2004. Strategies to overcome resistance to targeted protein kinase inhibitors. Nat. Rev. Drug Discov. 3: 1001 .

Davies H., Bignell G.R., Cox C., Stephens P., Edkins S., Clegg S., Teague J., Woffendin H., Garnett M.J., Bottomley W., Davis N., Dicks E., Ewing R., Floyd Y., Gray K., Hall S., Hawes R., Hughes J., Kosmidou V., Menzies A., Mould C., Parker A., Stevens C., Watt S., Hooper S., Wilson R., Jayatilake H., Gusterson B.A., Cooper C., Shipley J., Hargrave D., PritchardJones K., Maitland N., Chenevix-Trench G., Riggins G.J., Bigner D.D., Palmieri G., Cossu A., Flanagan A., Nicholson A., Ho J.W., Leung S.Y., Yuen S.T., Weber B.L., Seigler H.F., Darrow T.L., Paterson H., Marais R., Marshall C.J., Wooster R., Stratton M.R., and Futreal P.A. 2002. Mutations of the BRAF gene in human cancer. Nature 417: 949.

de Candia P., Solit D.B., Giri D., Brogi E., Siegel P.M., Olshen A.B., Muller W.J., Rosen N., and Benezra R. 2003. Angiogenesis impairment in Id-deficient mice cooperates with an Hsp90 inhibitor to completely suppress HER2/neu-dependent breast tumors. Proc. Natl. Acad. Sci. 100: 12337.

Demand J., Alberti S., Patterson C., and Hohfeld J. 2001. Cooperation of a ubiquitin domain protein and an E3 ubiquitin ligase during chaperone/proteasome coupling. Curr. Biol. 11: 1569.

de Rocha Dias S., Friedlos F., Light Y., Springer C., Workman P., and Marais R. 2005. Activated B-RAF is an Hsp90 client protein that is targeted by the anticancer drug 17-AAG. Cancer Res. (in press).

Deuerling E., Schulze-Specking A., Tomoyasu T., Mogk A., and Bukau B. 1999. Trigger factor and DnaK cooperate in folding of newly synthesized proteins. Nature 400: 693.

Dobson C.M. 1999. Protein misfolding, evolution and disease. Trends Biochem. Sci. 24: 329.

Dobson C.M. and Karplus M. 1999. The fundamentals of protein folding: Bringing together theory and experiment. Curr. Opin. Struct. Biol. 9: 92.

Drees B.E., Mills G.B., Rommel R., and Prestwich G.D. 2004. Therapeutic potential of phosphoinositide 3 kinase inhibitors. Expert Opin. Ther. Patents 14: 703.

Druker B. 2004. Molecularly targeted therapy: Have the floodgates opened? Oncologist 9: 357.

Du J., Widlund H.R., Horstmann M.A., Ramaswamy S., Ross K., Huber W.E., Nishimura E.K., Golub T.R., and Fisher D.E. 2004. Critical role of CDK2 for melanoma growth linked to its melanocyte-specific transcriptional regulation by MITF. Cancer Cell 6: 565.

Dymock B., Drysdale M., McDonald E., and Workman P. 2004. Inhibitors of Hsp90 and other chaperones for the treatment of cancer. Expert Opin. Ther. Patents 14: 837. 
Dymock B.W., Barril X., Brough P.A., Cansfield J.E., Massey A., McDonald E., Hubbard R.E., Surgenor A., Roughley S.D., Webb P., Workman P., Wright L., and Drysdale M.J. 2005. Novel, potent small-molecule inhibitors of the molecular chaperone Hsp90 discovered through structure-based design. $J$. Med. Chem. 48: 4212.

Egorin M.J., Rosen D.M., Wolff J.H., Callery P.S., Musser S.M., and Eiseman J.L. 1998. Metabolism of 17-(allylamino)-17demethoxygeldanamycin (NSC 330507) by murine and human hepatic preparations. Cancer Res. 58: 2385.

Egorin M.J., Lagattuta T.F., Hamburger D.R., Covey J.M., White K.D., Musser S.M., and Eiseman J.L. 2002. Pharmacokinetics, tissue distribution, and metabolism of 17-(dimethylaminoethylamino)-17-demethoxygeldanamycin (NSC 707545) in CD2F1 mice and Fischer 344 rats. Cancer Chemother. Pharmacol. 49: 7.

Frydman J. 2001. Folding of newly translated proteins in vivo. The role of molecular chaperones. Annu. Rev. Biochem. 70: 603.

Futreal A., Coin L., Marshall M., Down T., Hubbard T., Wooster R., Rahman N., and Stratton M.R. 2004. A census of human cancer genes. Nat. Rev. Cancer 4: 177. (For updates see: www.sanger.ac.uk/genetics/CGP/Census).

Garnett M.J. and Marais R. 2004. Guilty as charged: B-RAF is a human oncogene. Cancer Cell. 6: 313.

Garrett M.D., Walton M.I., McDonald E., Judson I., and Workman P. 2003. The contemporary drug development process: Advances and challenges in preclinical and clinical development. Prog. Cell Cycle Res. 5: 145.

Gething M.J. and Sambrook J. 2000. Protein folding in the cell. Nature 355: 33.

Goetz M.P., Toft D., Reid J., Ames M., Stensgard B., Safgren S., Adjei A.A., Sloan J., Atherton P., Vasile V., Salazaar S., Adjei A., Croghan G., and Erlichman C. 2005. Phase I trial of 17allylamino-17-demethoxygeldanamycin in patients with advanced cancer. J. Clin. Oncol. 23: 1078.

Gorre M.E., Mohammed M., Ellwood K., Hsu N., Paquette R., Rao P.N., and Sawyers C.L. 2001. Clinical resistance to STI571 cancer therapy caused by BCR-ABL gene mutation or amplification. Science 293: 876

Grem J.L., Morrison G., Guo X.D., Agnew E., Takimoto C.H., Thomas R., Szabo E., Grochow L., Grollman F., Hamilton J.M., Neckers L., and Wilson R.H. 2005. Phase I and pharmacologic study of 17-(allylamino)-17-demethoxygeldanamycin in adult patients with solid tumors. J. Clin. Oncol. 23: 1885 .

Guillard S., Clarke P.A., te Poele R., Di Stefano F., Raynaud F., and Workman P. 2004. Characterisation of a novel class 1 isoform selective phosphoratidyl-inositol 3-kinase inhibitor in glioma. Proceedings of the EORTC-NCI-AACR Symposium on Molecular Targets and Cancer Therapeutics (Abstr. 379). Eur. J. Cancer 2: 8. (Suppl.)

Guzi T. 2004. CYC-202 Cyclacel. Curr. Opin. Investig. Drugs 5: 1311 .

Hanahan D. and Weinberg R. 2000. The hallmarks of cancer. Cell 100: 57.

Hardcastle A., Boxall K., Richards J., Tomlin P., Sharp S., Clarke P., Workman P., and Aherne W. 2005. Solid-phase immunoassays in mechanism-based drug discovery: Their application in the development of inhibitors of the molecular chaperone heat-shock protein 90. Assay Drug Dev. Technol. 3: 273.

Hartl F.U. and Hayer-Hartl M. 2002. Molecular chaperones in the cytosol: From nascent chain to folded protein. Science 295: 1852

Hollingshead M., Alley M., Burger A.M., Borgel S., Pacula-Cox C., Fiebig H.H., and Sausville E.A. 2005. In vivo antitumor efficacy of 17-DMAG (17-dimethylaminoethylamino-17demethoxygeldanamycin hydrochloride), a water-soluble geldanamycin derivative. Cancer Chemother. Pharmacol. 56: 115.

Hopkins A.L. and Groom C.R. 2002. The druggable genome. Nat. Rev. Drug Discov. 1: 727.

Hostein I., Robertson D., DiStefano F., Workman P., and Clarke P.A. 2001. Inhibition of signal transduction by the HSP90 inhibitor 17-allylamino-17-demethoxygeldanamycin results in cytostasis and apoptosis. Cancer Res. 61: 4003.

International Human Genome Sequencing Consortium. 2004. Finishing the euchromatic sequence of the human genome. Nature 431: 931.

Isaacs J.S., Xu W., and Neckers L. 2003. Heat shock protein 90 as a molecular target for cancer therapeutics. Cancer Cell 3: 213.

Jackman A.L., Kaye S., and Workman P. 2004. The combination of cytotoxic and molecularly targeted therapies - Can it be done? Drug Discov. Today: Ther. Strategies 1: 445.

Jolly C. and Morimoto R.I. 2000. Role of the heat shock response and molecular chaperones in oncogenesis and cell death. J. Natl. Cancer Inst. 92: 1564.

Kamal A., Thao L., Sensintaffar J., Zhang L., Boehm M.F., Fritz L.C., and Burrows F.J. 2003. A high-affinity conformation of Hsp90 confers tumour selectivity on Hsp90 inhibitors. Nature 425: 407.

Kang S., Bader A.G., and Vogt P.K. 2005. Phosphatidylinositol 3-kinase mutations identified in human cancer are oncogenic. Proc. Natl. Acad. Sci. 102: 802.

Kaur G., Belotti D., Burger A.M., Fisher-Nielson K., Borsotti P., Riccardi E., Thillainathan J., Hollingshead M., Sausville E.A., and Giavazzi R. 2004. Antiangiogenic properties of 17(dimethylaminoethylamino)-17-demethoxygeldanamycin: An orally bioavailable heat shock protein 90 modulator. Clin. Cancer Res. 10: 4813.

Kelland L.R., Sharp S.Y., Rogers P.M., Myers T.G., and Workman P. 1999. DT-diaphorase expression and tumor cell sensitivity to 17-allylamino, 17-demethoxygeldanamycin, an inhibitor of heat shock protein 90. J. Natl. Cancer Inst. 91: 1940.

Kobayashi S., Boggon T.J., Dayaram T., Janne P.A., Kocher O., Meyerson M., Johnson B.E., Eck M.J., Tenen D.G., and Halmos B. 2005. EGFR mutation and resistance of non-small-cell lung cancer to gefitinib. N. Engl. J. Med. 352: 786.

Komarov P.G., Komarova E.A., Kondratov R.V., ChristovTselkov K., Coon J.S., Chernov M.V., and Gudkov A.V. 1999. A chemical inhibitor of $\mathrm{p} 53$ that protects mice from the side effects of cancer therapy. Science 285: 1733.

Komarova E.A., Neznanov N., Komarov P.G., Chernov M.V., Wang K., and Gudkov A.V. 2003. p53 inhibitor pifithrin alpha can suppress heat shock and glucocorticoid signaling pathways. J. Biol. Chem. 278: 15465.

Leaf C. 2004. Why we're losing the war on cancer-And how to win it. Fortune, March 12, 2004.

Liu D., Hutchinson O.C., Osman S., Price P., Workman P., and Aboagye E.O. 2002. Use of radiolabelled choline as a pharmacodynamic marker for the signal transduction inhibitor geldanamycin. Br. J. Cancer 87: 783.

Llorca O., Martin-Benito J., Grantham J., Ritco-Vonsovici M., Willison K.R., Carrascosa J.L., and Valpuesta J.M. 2001. The 'sequential allosteric ring' mechanism in the eukaryotic chaperonin-assisted folding of actin and tubulin. EMBO J. 20: 4065.

Llorca O., Martin-Benito J., Ritco-Vonsovici M., Grantham J., Hynes G.M., Willison K.R., Carrascosa J.L., and Valpuesta J.M. 2000. Eukaryotic chaperonin CCT stabilizes actin and tubulin folding intermediates in open quasi-native conformations. EMBO J. 19: 5971

Luders J., Demand J., and Hohfeld J. 2000. The ubiquitin-related BAG-1 provides a link between the molecular chaperones Hsc70/Hsp70 and the proteasome. J. Biol. Chem. 275: 4613.

Lynch T.J., Bell D.W., Sordella R., Gurubhagavatula S., Okimoto R.A., Brannigan B.W., Harris P.L., Haserlat S.M., Supko J.G., Haluska F.G., Lois D.N., Christiani D.C., Settleman J., and Haber D.A. 2004. Activating mutations in the epidermal growth factor receptor underlying responsiveness of non-small-cell lung cancer to gefitinib. N. Engl. J. Med. 350: 2129.

MacCallum D.E., Melville J.E., Frames S., Watt K., Anderson S., Gianella-Borradori A., Lane D.P., and Green S.R. 2005. Seliciclib (CYC202, R-roscovitine) induces cell death in multiple myeloma cells by inhibition of RNA polymerase II-dependent transcription and down-regulation of Mcl-1. Cancer Res. 65: 5399.

Maloney A. and Workman P. 2002. HSP90 as a new therapeutic 
target for cancer therapy: The story unfolds. Expert Opin. Biol. Ther. 2: 3.

Maloney A., Clarke P.A., and Workman P. 2003. Genes and proteins governing the cellular sensitivity to HSP90 inhibitors: A mechanistic perspective. Curr. Cancer Drug Targets 3: 331.

Manning G., Whyte D.B., Martinez R., Hunter T., and Sudarsanam S. 2002. The protein kinase complement of the human genome. Science 298: 1912.

Mitsiades C.S., Mitsiades N., Hideshima T., Richardson P.G., and Anderson K.C. 2005. Proteasome inhibition as a therapeutic strategy for hematologic malignancies. Expert Rev. Anticancer Ther. 5: 465.

Morimoto R.I. 1998. Regulation of the heat shock transcriptional response: Cross talk between family of heat shock factors, molecular chaperones and regulators. Genes Dev. 12: 3788 .

Mosser D. and Morimoto R.I. 2004. Molecular chaperones and the stress of oncogenesis. Oncogene. 23: 2907.

Newbatt Y., Burns S., Hayward R., Whittaker S.R., Kirk R., Marshall C.S., Springer C.J., McDonald E., Cancer Genome Project., Marais R., Workman P., and Aherne G.W. 2005. Identification of inhibitors of the kinase activity of oncogenic V600E BRAF in an enzyme cascade high throughput screen. J. Biomol. Screen. (in press).

Nowell P.C. 1976. The clonal evolution of tumor cell populations. Science 194: 23.

Nutley B.P., Raynaud F.I., Wilson S.C., Fischer P.M., Hayes A., Goddard P.M., McClue S.J., Jarman M., Lane D.P., and Workman P. 2005. Metabolism and pharmacokinetics of the cyclin-dependent kinase inhibitor R-roscovitine in the mouse. Mol. Cancer Ther. 4: 125.

Orteaga S., Prieto I., Odajima J., Martín A., Dubus P., Sotillo R., Barbero J.L., Malumbres M., and Barbacid M. 2003. Cyclindependent kinase 2 is essential for meiosis but not for mitotic cell division in mice. Nat. Genet. 35: 25.

Paez J.G., Jänne P.A., Lee J.C., Tracy S., Greulich H., Gabriel S., Herman P., Kaye F.J., Lindeman N., Boggon T.J., Naoki K., Sasaki H., Fujii Y., Eck M.J., Sellers W.R., Johnson B.E., and Meyerson M. 2004. EGFR mutations in lung cancer: Correlation with clinical response to gefitinib therapy. Science 304: 1497.

Panaretou B., Siligardi G., Meyer P., Maloney A., Sullivan J.K., Singh S., Millson S.H., Clarke P.A., Naaby-Hansen S., Stein R., Cramer R., Mollapour M., Workman P., Piper P.W., Pearl L.H., and Prodromou C. 2002. Activation of the ATPase activity of HSP90 by the stress-regulated cochaperone aha1. Mol. Cell 10: 1307.

Pao W., Miller V.A., Politi K.A., Riely G.J., Somwar R., Zakowski M.F., Kris M.G., and Varmus H. 2005. Acquired resistance of lung adenocarcinomas to gefitinib or erlotinib is associated with a second mutation in the EGFR kinase domain. PLoS Med. 2: e73.

Pao W., Miller V., Zakowski M., Doherty J., Politi K., Sarkaria I., Singh B., Heelan R., Rusch V., Fulton L., Mardis E., Kupfer D., Wilson R., Kris M., and Varmus H. 2004. EGF receptor gene mutations are common in lung cancers from "never smokers" and are associated with sensitivity of tumors to gefitinib and erlotinib. Proc. Natl. Acad. Sci. 101: 13306.

Patel S., Saghir N., Zhyvoloup A., Lensun L., Pergl-Wilson G., Depledge P., Eccles S., Kelland L.R., Clarke P.A., Ahmadi K., Raynaud F.I., Di Stefano F., Workman P., and Alderton W. 2004. Identification of potent selective inhibitors of PI3K as candidate anticancer drugs. Proc. Am. Assoc. Cancer Res. (Abstract LB-247).

Prodromou C., Roe S.M., O’Brien R., Ladbury J.E., Piper P.W., and Pearl L.H. 1997. Identification and structural characterization of the ATP/ADP-binding site in the HSP90 molecular chaperone. Cell 90: 65.

Radford S.E. 2000. Protein folding: Progress made and promises ahead. Trends Biochem. Sci. 25: 611.

Raynaud F.I., Fischer P.M., Nutley B.P., Goddard P.M., Lane D.P., and Workman P. 2004. Cassette dosing pharmacokinetcs of a library of 2,6,9-trisubstituted purine CDK2 inhibitors prepared by parallel synthesis. Mol. Cancer Ther. 3: 353.

Raynaud F.I., Whittaker S.R., Fischer P.M., McClue S., Walton
M.I., Barrie S.E., Garrett M.D., Rogers P., Clarke S.J., Kelland L.R., Valenti M., Brunton L., Eccles S., Lane D.P., and Workman P. 2005. In vitro and in vivo pharmacokinetic-pharmacodynamic relationships for the trisubstituted aminopurine cyclin-dependent kinase inhibitors olomoucine, bohemine and CYC202. Clin. Cancer Res. 11: 4875.

Roe S.M., Prodromou C., O’Brien R., Ladbury J.E., Piper P.W., and Pearl L.H. 1999. Structural basis for inhibition of the Hsp90 molecular chaperone by the antitumour antibiotics radicicol and geldanamycin. J. Med. Chem. 42: 260.

Rowlands M.G., Newbatt Y.M., Prodromou C., Pearl L.H., Workman P., and Aherne W. 2004. High-throughput screening assay for inhibitors of heat-shock protein 90 ATPase activity. Anal. Biochem. 327: 176.

Rutherford S.L. and Lindquist S. 1998. HSP90 as a capacitor for morphological evolution. Nature 396: 336.

Samuels Y., Wang Z. Bardelli N., Ptak J., Szabo S., Yan H., Gazder A., Powell S.M., Riggins G.J., Willison J.K., Markowitz S., Kinzler K.W., Vogelstein B., and Velculescu V.E. 2004. High frequency of mutations of the PIK3CA gene in the human cancer. Science 23: 304.

Sangster T.A., Quietsch C., and Lindquist S. 2003. HSP90 and chromatin. Where is the link? Cell Cycle 2: 166.

Sawyers C.L. 2003. Opportunities and challenges in the development of kinase inhibitor therapy for cancer. Genes Dev. 17: 2998.

Scheufler C., Brinker A., Bourenkov G., Pegoraro S., Moroder L., Bartunik H., Hartl F.U., and Moarefi I. 2000. Structure of TPR domain-peptide complexes: Critical elements in the assembly of the Hsp70-Hsp90 multichaperone machine. Cell 101: 199.

Schnieder C., Sepp-Lorenzino L., Nimmesgern E., Ouerfelli O., Danishefsky S., Rosen N., and Hartl F.U. 1996. Pharmacologic shifting of a balance between protein refolding and degradation mediated by HSP90. Proc. Natl. Acad. Sci. 93: 14536.

Schnur R.C., Corman M.L., Gallaschun R.J., Cooper B.A., Dee M.F., Doty J.L., Muzzi M.L., DiOrio C.I., Barbacci E.G., Miller P.E., Pollack V.A., Savage D.M., Sloan D.E., Pustilnik L.R., Moyer J.D., and Moyer M.P. 1995a. ErbB-2 oncogene inhibition by geldanamycin derivatives: Synthesis, mechanism of action, and structure-activity relationships. J. Med. Chem. 38: 3813 .

Schnur R.C., Corman M.L., Gallaschun R.J., Cooper B.A., Dee M.F., Doty J.L., Muzzi M.L., Moyer J.D., DiOrio C.I., Barbacci E.G., Miller P.E., O'Brien A.T., Morin M.J., Foster B.A., Pollack V.A., Savage D.M., Sloan D.E., Pustilnik L.R., and Moyer M.P. 1995b. Inhibition of the oncogene product p185erbB-2 in vitro and in vivo by geldanamycin and dihydrogeldanamycin derivatives. J. Med. Chem. 38: 3806.

Schulte T.W., Blagosklonny M.V., Ingui C., and Neckers L. 1995. Disruption of the Raf-1-HSP90 molecular complex results in destabilization of Raf-1 and loss of Raf-1-Ras association. J. Biol. Chem. 270: 24585.

Shah N.P., Tran C., Lee F.Y., Chen P., Norris D., and Sawyers C.L. 2004. Overriding imatinib resistance with a novel ABL kinase inhibitor. Science 305: 399.

Sharp S.Y., Kelland L.R., Valenti M.R., Brunton L.A., Hobbs S., and Workman P. 2000. Establishment of an isogenic human colon tumor model for NQO1 gene expression: Application to investigate the role of DT-diaphorase in bioreductive drug activation in vitro and in vivo. Mol. Pharmacol. 58: 1146.

Shayesteh L., Lu Y., Kuo W.L., Baldocchi R., Godfrey T., Collins C., Pinkel D., Powell B., Mills G.B., and Gray J.W. 1999. PIK3CA is implicated as an oncogene in ovarian cancer. Nat. Genet. 21: 99.

Sherr C.J. 1996. Cancer cell cycles. Science 274: 1672.

. 2000. The Pezcoller Lecture: Cancer cell cycles revisited. Cancer Res. 60: 3689.

Smith N.F., Hayes A., Nutley B.P., Raynaud F.I., and Workman P. 2004. Evaluation of the cassette dosing approach for assessing the pharmacokinetics of geldanamycin analogues in mice. Cancer Chemother. Pharmacol. 54: 475.

Smith V., Hobbs S., Court W., Eccles S., Workman P., and Kelland L.R. 2002. ErbB2 overexpression in an ovarian cancer 
cell line confers sensitivity to the HSP90 inhibitor geldanamycin. Anticancer Res. 22: 1993.

Smith-Jones P.M., Solit D.B., Akhurst T., Afroze F., Rosen N., and Larson S.M. 2004. Imaging the pharmacodynamics of HER2 degradation in response to Hsp90 inhibitors. Nat. Biotechnol. 22: 701.

Solit D.B., Scher H.I., and Rosen N. 2003. Hsp90 as a therapeutic target in prostate cancer. Semin. Oncol. 30: 709.

Sordella R., Bell D.W., Haber D.A., and Settleman J. 2004. Gefitinib-sensitizing EGFR mutations in lung cancer activate anti-apoptotic pathways. Science 305: 1163.

Stebbins C.E., Russo A.A., Schneider C., Rosen N., Hartl F.U., and Pavletich N.P. 1997. Crystal structure of an Hsp90-geldanamycin complex: Targeting of a protein chaperone by an antitumor agent. Cell 89: 239.

Stein R. and Waterfield M.D. 2000. PI3-kinase inhibition: A target for drug development? Mol. Med. Today. 6: 347.

Sydor J.R., Pien C.S., Zhang Y., Ali J., Dembski M.S., Ge J., Grenier L., Hudak J., Normant E., Pak R., Patterson J., Pink M., Sang J., Woodward C., Mitsiades C.S., Anderson K.C., Grayzel D.S., Wright J., Tong J.K., Adams J., Palombella V.J., and Barrett J.A. 2005. Anti-tumor activity of a novel, water soluble Hsp90 inhibitor IPI-504 in multiple myeloma. Proc. Am. Assoc. Cancer Res. (Abstract 6160).

Tetsu O. and McCormick F. 2003. Proliferation of cancer cells despite CDK2 inhibition. Cancer Cell 3: 233.

Thulasiraman V., Yang C.F., and Frydman J. 1999. In vivo newly translated polypeptides are sequestered in a protected folding environment. $E M B O J$. 18: 85 .

Valpuesta J.M., Martin-Benito J., Gomez-Puertas P., Carrascosa J.L., and Willison K.R. 2002. Structure and function of a protein folding machine: The eukaryotic chaperonin CCT. FEBS Lett. 529: 11.

Vivanco I. and Sawyers C.L. 2002. The phosphatidylinositol 3kinase AKT pathway in human cancer. Nat. Rev. Cancer 2: 489.

Vogelstein B. and Kinzler K.W. 2004. Cancer genes and the pathways they control. Nat. Med. 10: 789 .

Walton M.I., Wilson S.C., Hardcastle I.R., Mirza A.R., and Workman P. 2005. An evaluation of the ability of pifithrin- $\alpha$ and $-\beta$ to inhibit $p 53$ function in two wild type p53 human tumour lines. Mol Cancer Ther. 4: 1369.

Wan T.C, Garnett M.J., Roe S.M., Lee S., Niculescu-Duvaz D., Good V.M., Jones C.M, Marshall C.J., Springer C.J, Barford D., and Marais R. 2004. Mechanism of activation of the RAFERK signalling pathway by oncogenic mutations of B-RAF. Cell 116: 855 .

Wang S., Sakai H., and Weidmann M. 1995. NAC covers ribosome-associated nascent chains thereby forming a protective environment for regions of nascent chains just emerging from the peptidyl transferase center. J. Cell Biol. 130: 519.

Wang Z., Shen D., Parsons D.W., Bardelli A., Sager J., Szabo S., Ptak J., Silliman N., Peters B.A., van der Hejden M.S., Parmigiani G., Yan H., Wang T.L., Riggins G., Powell S.M., Willison J.K., Markowitz S., Kinzler K.W., Vogelstein B., and Velculescu V.E. 2004. Mutational analysis of the tyrosine phosphatome in colorectal cancers. Science 304: 1164.

Ward S.G., Sotsios Y., Dowden J., Bruce I., and Finan P. 2003. Therapeutic potential of phosphoinositide 3-kinase inhibitors. Chem. Biol. 10: 207.

Wegele H., Muller L., and Buchner J. 2004. Hsp70 and Hsp90A relay team for protein folding. Rev. Physiol. Biochem. Pharmacol. 151: 1 .

Weinstein I.B. 2002. Cancer. Addiction to oncogenes-The Achilles heal of cancer. Nature 297: 63.

Weir B., Zhao X., and Meyerson M. 2004. Somatic alterations in the human cancer genome. Cancer Cell 6: 433.

Whitesell L., Bagatell R., and Falsey R. 2003. The stress response: Implications for the clinical development of Hsp90 inhibitors. Curr. Cancer Drug Targets 3: 349.

Whittaker S.R., Walton M.I., Garrett M.D., and Workman P. 2004. The cyclin-dependent kinase inhibitor CYC202 (Rroscovitine) inhibits retinoblastoma protein phosphorylation, causes loss of cyclin D1 and activates the mitogen-activated protein kinase pathway. Cancer Res. 64: 262.

Whittaker S.R., te Poele R., Walton M.I., Garrett M.D., and Workman P. 2003. Gene expression profiling of the cyclin-dependent kinase inhibitor CYC202 (R-roscovitine). Proc. Am. Assoc. Cancer Res. (Abstract 3996.)

Wilhelm S.M., Carter C., Tang L., Wilkie D., McNabola A., Rong H., Chen C., Zhang X., Vincent P., McHugh M., Cao Y., Shujath J., Gawlak S., Eveleigh D., Rowley B., Liu L., Adnane L., Lynch M., Auclair D., Taylor I., Gedrich R., Voznesensky A., Riedl B., Post L.E., Bollag G., and Trail P.A. 2004. BAY 43-9006 exhibits broad spectrum oral antitumor activity and targets the RAF/MEK/ERK pathway and receptor tyrosine kinases involved in tumor progression and angiogenesis. Cancer Res. 64: 7099.

Workman P. 2001. Paul Workman - At the cutting edge of drug discovery (interview by Dorothy Bonn). Lancet Oncol. 2: 113 . . 2002. Challenges of PK/PD measurements in modern drug development. Eur. J. Cancer 18: 2189.

- 2003a. Strategies for treating cancers caused by multiple genomic abnormalities: From concepts to cures? Curr. Opin. Investig. Drugs 12: 1415.

. 2003b. The opportunities and challenges of personalized genome-based molecular therapies for cancer: Targets, technologies, and molecular chaperones. Cancer Chemother. Pharmacol. (suppl. 1) 52: S45.

.2003c. Paul Workman on the challenges of cancer drug development. Interview by Katherine E. Pestell. Drug Discov. Today 8: 775 .

. 2003d. How much gets there and what does it do?: The need for better pharmacokinetic and pharmacodynamic endpoints in contemporary drug discovery and development. Curr. Pharm. Des. 9: 891.

2003e. Auditing the pharmacological accounts for HSP90 inhibitors. Unfolding the relationship between pharmacokinetics and pharmacodynamics. Mol. Cancer Ther. 2: 131.

. 2003f. Overview: Translating HSP90 biology into Hsp90 drugs. Curr. Cancer Drug Targets 3: 297.

. 2004a. Inhibiting the phosphoinositide 3-kinase pathway for cancer treatment. Biochem. Soc. Trans. 32: 393.

. 2004b. Combinatorial attack on multistep oncogenesis by inhibiting the Hsp90 molecular chaperone. Cancer Lett. 206: 149.

- 2004c. Altered states: Selectively drugging the HSP90 cancer chaperone. Trends Mol. Med. 109: 47.

-2005. Genomics and the second golden era of cancer research. Mol. BioSystems 1: 17.

Workman P. and Kaye S.B. 2002. Translating basic cancer research into new cancer therapeutics. Trends Mol. Med. 8: S1S8.

Workman P., Raynaud F., Clarke P.A., te Poele R., Eccles S., Kelland L., Di Stefano F., Ahmadi K., Parker P. and Waterfield M. 2004. Pharmacological properties and in vitro and in vivo antitumour activity of the potent and selective PI3 kinase inhibitor PI103. Proceedings of the EORTC-NCI-AACR Symposium on Molecular Targets and Cancer Therapeutics (Abstr. 414A). Eur. J. Cancer 2: 8. (Suppl.)

Wright L., Barril X., Dymock B., Sheridan L., Surgenor A., Beswick M., Drysdale M., Collier A., Massey A., Davies N., Fink A., Fromont C., Aherne W., Boxall K., Sharp S., Workman P., and Hubbard R.E. 2004. Structure-activity relationships in purine-based inhibitor binding to HSP90 isoforms. Chem. Biol. 11: 775.

Xu W., Yuan X., Xiang Z., Mimnaugh E., Marcu M., and Neckers L. 2005. Surface charge and hydrophobicity determine ErbB2 binding to the Hsp90 chaperone complex. Nat. Struct. Mol. Biol. 12: 120.

Young J.C., Moarefi I., and Hartl F.U. 2001. Hsp90: A specialised but essential protein-folding tool. J. Cell Biol. 154: 267.

Young J.C., Agashe V.R., Siegers K., and Hartl F.U. 2004. Pathways of chaperone-mediated protein folding in the cytosol. Nat. Rev. Mol. Cell Biol. 5: 781. 


\section{DRUGGING THE CANCER KINOME}

Yu X., Guo Z.S., Marcu M.G., Neckers L., Nguyen D.M., Chen G.A., and Schrump D.S. 2002. Modulation of p53, ErbB1, ErbB2, and Raf-1 expression in lung cancer cells by depsipeptide FR901228. J. Natl. Cancer Inst. 94: 504.

Zhang L., Yu J., Park B.H., Kinzler K.W., and Vogelstein B. 2000. Role of BAX in the apoptotic response to anticancer agents. Science 290: 989.

Zhao R., Davey M., Hsu Y.C., Kaplanek P., Tong A., Parsons A.B., Krogan N., Cagney G., Mai D., Greenblatt J., Boone C., Emili A., and Houry W.A. 2005. Navigating the chaperone network: An integrative map of physical and genetic interactions mediated by the HSP90 chaperone. Cell 120: 715. 


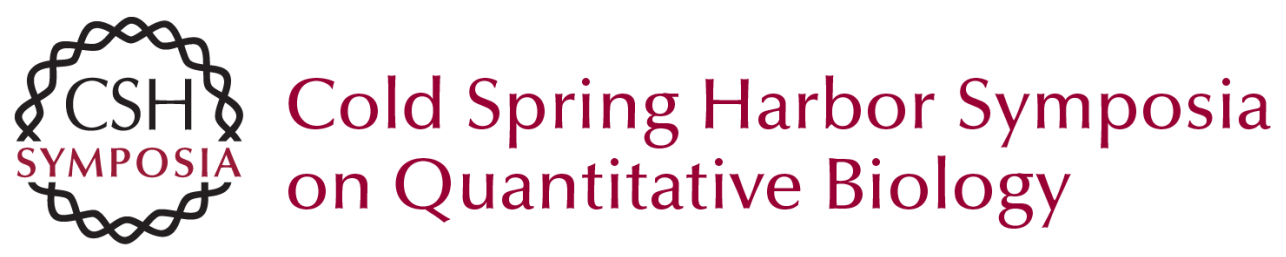

\section{Drugging the Cancer Kinome: Progress and Challenges in Developing Personalized Molecular Cancer Therapeutics}

P. WORKMAN

Cold Spring Harb Symp Quant Biol 2005 70: 499-515

Access the most recent version at doi:10.1101/sqb.2005.70.020

References This article cites 158 articles, 50 of which can be accessed free at: http://symposium.cshlp.org/content/70/499.full.html\#ref-list-1

License

Email Alerting Receive free email alerts when new articles cite this article - sign up in Service the box at the top right corner of the article or click here. 